\title{
Cardiac Stimulation in the Third Millennium: Where Do We Head from Here?
}

\author{
Mauro Biffi ${ }^{1}$, Alberto Spadotto ${ }^{1,2} \mathbb{D}$, Giuseppe Pio Piemontese ${ }^{1,2, *}$, Sebastiano Toniolo ${ }^{1,2} \mathbb{D}$, Lorenzo Bartoli ${ }^{1,2} \mathbb{D}$, \\ Sergio Sorrentino 1,2, Alessandro Minguzzi 1,2, Giulia Massaro 1,2 ${ }^{\mathbb{D}}$, Claudio Capobianco ${ }^{1,2}$ \\ and Giovanni Statuto $1,2 \mathbb{D}$
}

1 Unit of Cardiology, Azienda Ospedaliero-Universitaria di Bologna, 40138 Bologna, Italy; mauro.biffi@aosp.bo.it (M.B.); alberto.spadotto@studio.unibo.it (A.S.); sebastiano.toniolo@studio.unibo.it (S.T.); lorenzo.bartoli4@studio.unibo.it (L.B.); sergio.sorrentino@studio.unibo.it (S.S.); alessandro.minguzzi2@studio.unibo.it (A.M.); giulia.massaro@unibo.it (G.M.); claudio.capobianco@studio.unibo.it (C.C.); giovanni.statuto@studio.unibo.it (G.S.)

2 Department of Experimental, Diagnostic and Specialty Medicine, Università Alma Mater Studiorum di Bologna, 40138 Bologna, Italy

* Correspondence: giuseppe.piemontese4@studio.unibo.it

check for updates

Citation: Biffi, M.; Spadotto, A.; Piemontese, G.P.; Toniolo, S.; Bartoli, L.; Sorrentino, S.; Minguzzi, A.; Massaro, G.; Capobianco, C.; Statuto, G. Cardiac Stimulation in the Third Millennium: Where Do We Head from Here? Hearts 2021, 2, 15-35. https://doi.org/10.3390/ hearts2010003

Received: 19 November 2020 Accepted: 31 December 2020 Published: 6 January 2021

Publisher's Note: MDPI stays neutral with regard to jurisdictional clai$\mathrm{ms}$ in published maps and institutional affiliations.

Copyright: (C) 2021 by the authors. Licensee MDPI, Basel, Switzerland. This article is an open access article distributed under the terms and conditions of the Creative Commons Attribution (CC BY) license (https:// creativecommons.org/licenses/by/ $4.0 /)$.

\begin{abstract}
Over the years, pacemakers have evolved from a life-saving tool to prevent asystole to a device to treat heart rhythm disorders and heart failure, aiming at improving both cardiac function and clinical outcomes. Cardiac stimulation nowadays aims to correct the electrophysiologic roots of mechanical inefficiency in different structural heart diseases. This has led to awareness of the concealed risks of customary cardiac pacing that can inadvertently cause atrioventricular and inter/intra-ventricular dyssynchrony, and has promoted the development of new pacing modalities and the use of stimulation sites different from the right atrial appendage and the right ventricular apex. The perspective of truly physiologic pacing is the leading concept of the continued research in the past 30 years, which has made cardiac stimulation procedure more sophisticated and challenging. In this article, we analyze the emerging evidence in favor of the available strategies to achieve an individualized physiologic setting in bradycardia pacing.
\end{abstract}

Keywords: cardiac stimulation; atrioventricular coupling; physiologic pacing; clinical outcome; individualized therapy

\section{Introduction}

The development of pacemaker technology in the $1950 \mathrm{~s}^{\prime}$ focused on creating an implantable ventricular device to prevent death from asystole. In the following years, technologic developments enabled restoration of sequential activation between the atrium and ventricle in a view to maintain the hemodynamics of bradyarrhythmia patients, preventing heart failure and atrial fibrillation. Eventually, cardiac resynchronization therapy (CRT) devices were developed to treat heart failure (HF) due to systolic left ventricular (LV) dysfunction with a broad QRS [1]. Furthermore, modern devices are instrumental to patient monitoring, enabling prompt detection of clinical issues and streamlined device follow-up [2].

The aim to restore a normal cardiac physiology, despite conduction system disease, is still ongoing after 60 years of cardiac pacing, in a quest of truly physiologic pacing that stems from the occurrence of symptomatic LV dysfunction/heart failure in 12-20\% patients treated by right ventricular (RV) pacing, despite maintenance of atrioventricular (AV) coupling [3].

An ideal model of stimulation is based on maintenance of the physiologic cardiac activation: atrioventricular, interventricular, and intraventricular. The goal is to achieve the optimal ventricular preload by enabling normal interatrial and atrioventricular (AV) 
coupling, which portends a normal stroke volume once physiologic ventricular activation ensues. This concept is challenging in the context of bradycardia therapy and unfolds in multiple ways in clinical practice.

The key points stemming out of medical literature and leading into the future of cardiac stimulation are:

- Atrial-based pacing and maintenance of atrioventricular (AV) coupling;

- The detrimental effect of right ventricular (RV) stimulation;

- The role of AV timing and of RV pacing minimization;

- His bundle and conduction system pacing to preserve physiologic AV timing and ventricular activation;

- Minimization of device related complications by leadless cardiac stimulation.

\section{Indications for Cardiac Pacing}

Pacing therapy is indicated in symptomatic patients with sinus node disease (SND), in permanent or intermittent high-grade atrioventricular block (AVB), and in neurally mediated syncope (NMS). CRT is indicated in HF patients with QRS duration > $130 \mathrm{ms,}$ particularly in left bundle branch block (LBBB) patients. To date, the main indications for pacemaker implantation include atrioventricular block (AVB, about $65 \%$ of patients), sinus node disease (SND) in 20\%, atrial fibrillation (AF) plus bradycardia in (10-15\%) [4].

\subsection{Atrial Pacing: Interatrial and Atrioventricular Coupling}

In symptomatic sinus node disease (SND), atrial pacing is used to prevent sinus bradycardia/asystole and/or to treat chronotropic incompetence by rate responsiveness. The right atrium appendage (RAA) is most commonly used for lead placement owing to lead stability and safety. While appropriate for atrial sensing, this location is suboptimal for pacing: RAA pacing was reported to prolong the AV conduction time in nearly $50 \%$ patients, thereby creating a first degree AVB in some of them (Figure 1) [5].

Paced atrial activation occurs outside the preferential conduction of Bachmann bundles, possibly resulting in delayed depolarization of the left atrium, which can occur late compared to AV conduction thus compromising LV preload [6]. Though the paced AV is programmed at least $30-50 \mathrm{~ms}$ longer than the sensed AV interval to allow a suitable end-diastolic ventricular filling, such a non-physiological atrial activation is associated with worse clinical outcomes, mainly heart failure (HF) [6] and atrial fibrillation (AF) $[7,8]$. Their incidence depends on the underlying atrial substrate and on the amount of atrial stimulation (AP) being delivered.

AF is highly prevalent both before and after PM implantation, almost 50\% of SND patients [7]. In this population, it has been observed that diabetes, hypertension, and left atrial enlargement are AF predictors, suggesting that they portend an underlying vulnerable atrial substrate [9]. Though AP prevents bradycardia-dependent tachyarrhythmias, several patients experience new-onset AF [8]. The atrial stimulation site seems to impact on the risk of new-onset AF more than AP percentage. High-septal atrial pacing near Bachmann's bundle seems to prevent the negative effects of RAA pacing: proximity to Bachmann's bundle decreases interatrial and AV conduction delay [10]. 


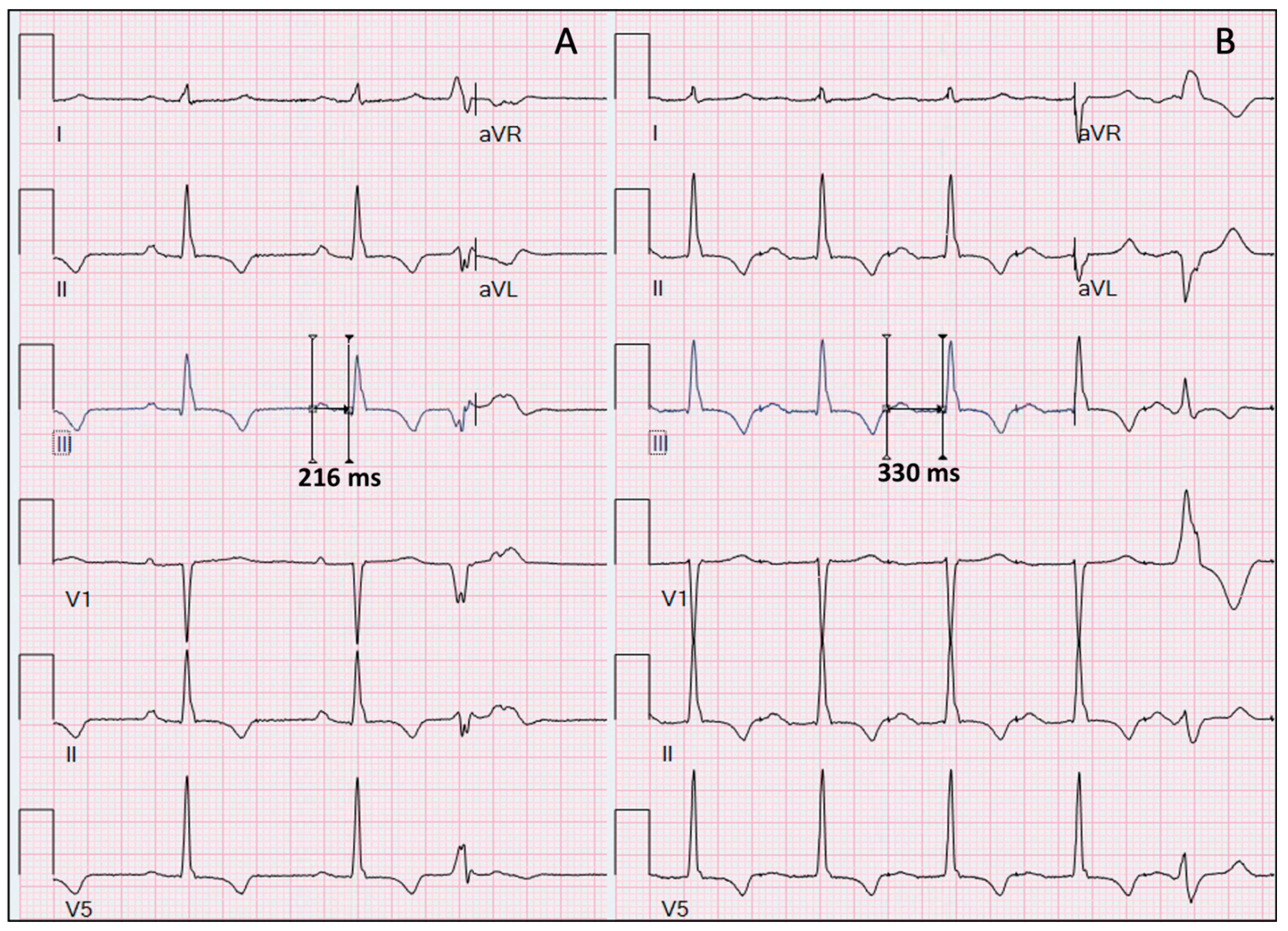

Figure 1. Prolongation of the atrioventricular interval (114 ms) due to atrial stimulation. Flattening and increased paced $\mathrm{P}$ wave duration is also observed. (A) Sinus rhythm 62 bpm: normal atrioventricular (AV) conduction and P wave duration; (B) paced atrium $80 \mathrm{bpm}$ : prolonged AV conduction and $\mathrm{P}$ wave duration.

In EPASS (Electrophysiology-Guided Pacing Site Selection) trial, low interatrial septum (IAS) pacing was also superior to RAA pacing in preventing persistent or permanent $\mathrm{AF}$ in patients with SND and intra-atrial conduction delay. This could possibly be related to decreased interatrial conduction time. Consistently, low IAS and RAA pacing were not significantly different in absence of interatrial conduction delay [11]. Bachmann bundle pacing slowed the progression from paroxysmal to chronic AF in a randomized multicenter trial [12]. Though easily accessible, the atrial appendage seems rarely the preferred pacing site in patients with brady-tachy syndrome, and sets the physiologic background for pacing close to the Bachmann bundle in patients with delayed interatrial conduction, as identified by a $\geq 120 \mathrm{~ms} P$ wave duration or markedly prolonged paced $\mathrm{P}$ wave/PR interval from the RAA $[13,14]$. Careful analysis of unpaced and paced $P$ wave duration and PR interval can unveil AP-induced dyssynchrony (Figure 1). Noteworthy, unnecessary atrial stimulation reproducibly increased new-onset AF both in ICD (Implantable Cardioverter-Defibrillator) and in CRTD (Cardiac Resynchronization Therapy Defibrillator) recipients [15,16].

In the remaining $70 \%$ of patients without SSS (Sick Sinus Syndrome) and in CRT recipients, the main function of the right atrial lead is detecting the $P$ wave to ensure AV coupling. This is the typical scenario for paroxysmal/persistent AVB and CRT, where RAA placement enables reliable atrial sensing. Single lead VDD pacemakers were developed to minimize lead-related complications when atrial stimulation is redundant $[17,18]$.

To date, a conservative programming of lower rate limit (LRL) and rate responsiveness is recommended especially in HF and LV dysfunction patients, with the aim of preserving 
interatrial and $\mathrm{AV}$ conduction, despite marked sinus bradycardia. To minimize the percentage of atrial stimulation, LRL should be set $\leq 40 \mathrm{bpm}$ [19]. Conversely, in SND, the LRL can be set between 50 and $60 \mathrm{bpm}$, and rate responsiveness can be activated in order to improve symptoms and exercise tolerance.

\subsection{AV Conduction and Ventricular Pacing}

The role of AV conduction on cardiac hemodynamic has been studied for almost 30 years, highlighting the importance of a physiologic diastolic filling. Second (2nd) and third (3rd) degree AVB completely disrupt ventricular preload by atrioventricular uncoupling, atrial kick occurring frequently against closed $\mathrm{AV}$ valves or randomly during diastole. A long PR interval can also be detrimental by anticipation of atrial systole over ventricular systole, so atrial contraction occurs during the early diastolic LV-filling phase (Figure 2). Hence, atrial contribution to LV ventricular filling is reduced, as easily detected by echocardiography: a relatively early A wave overlaps with a relatively late $\mathrm{E}$ wave, resulting in a shortening of LV diastolic filling time [20] (Figure 2). Furthermore, the prolongation of the PR interval is associated with delayed mitral valve closure, which may cause an end-diastolic mitral regurgitation, adding further stroke volume reduction [21]. Physiologic pacing means programming an AV delay that restores ventricular preload and corrects mitral regurgitation [22,23]. However, large randomized clinical trials in mixed populations of pacemaker recipients failed to prove a mortality benefit over VVI pacing, mainly due to untailored LRL and AV intervals. In the CTOPP (Canadian Trial of Physiological Pacing) trial, 2568 patients scheduled for a first implantation of a pacemaker were randomly assigned to VVI or DDD pacing. After a mean follow-up of 3 years, no difference in cardiovascular death or stroke occurred in the two groups, while AF incidence was significantly decreased by DDD pacing [24]. In the MOST (Mode Selection Trial) trial, 2010 patients with SND were randomly assigned to DDD pacing or VVI pacing, and were followed for a median of 33 months. The study failed to prove a superiority of physiological pacing in terms of death from any cause or non-fatal stroke. Dual-chamber pacing reduced the risk of AF and of heart failure, and slightly improved the quality of life compared to ventricular pacing [25]. The UK-PACE (United Kingdom Pacing and Cardiovascular Events) trial tested the same hypothesis in the setting of AVB. In elderly patients with high-grade AVB, the pacing mode had no effect on all-cause mortality, AF, $\mathrm{HF}$, or a composite of stroke, transient ischemic attack, or other thromboembolism [26]. A more recent meta-analysis of five randomized trials on DDD vs. VVI pacing confirmed the absence of significant reduction in mortality or heart failure, confirming the significant impact on AF; stroke reduction appeared of borderline significance [27]. 


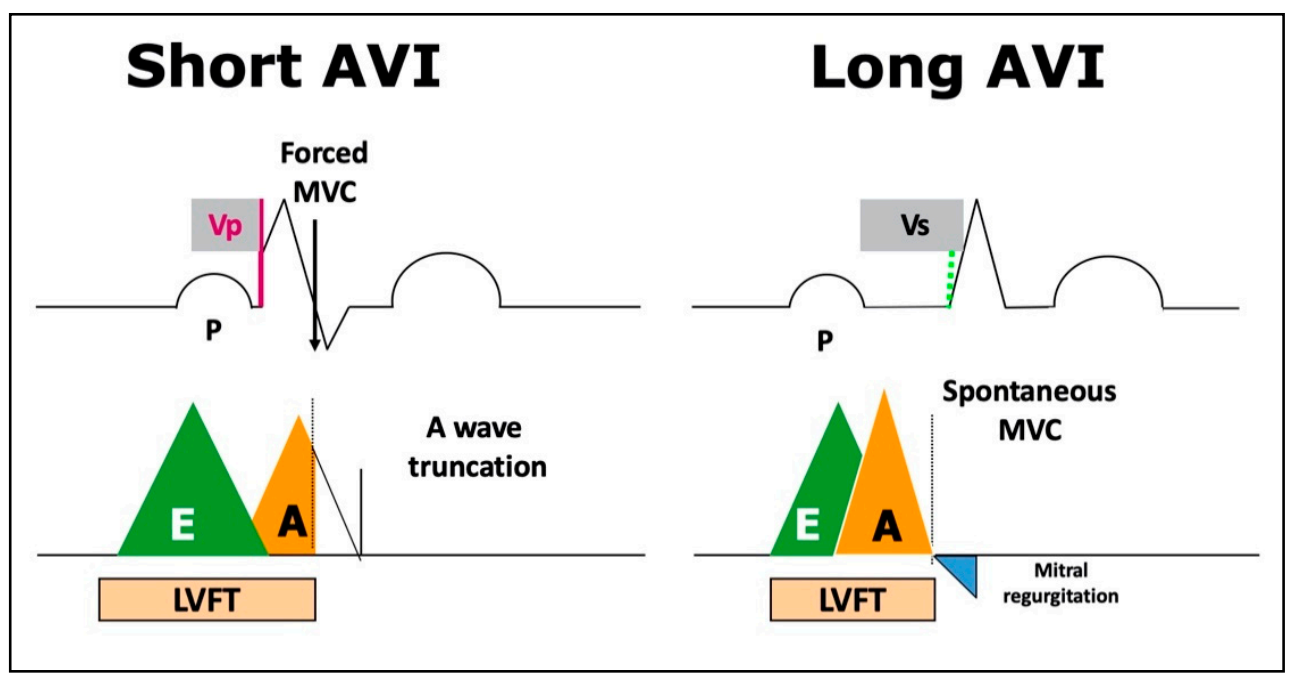

Figure 2. Hemodynamic effects of a short or a long atrioventricular interval (AVI) on left ventricular filling time (LVFT). A short AVI results in truncation of the A wave because of atrial kick against a closed mitral valve, while a long AVI causes E/A overlap and passive functional mitral regurgitation in end-diastole owing to delayed mitral valve closure (MVC).

\subsubsection{The Role of Ventricular Activation}

Right Ventricular (RV) endocardial stimulation worsens LV systolic and diastolic function, with possible detrimental clinical effects representing the RV pacing-induced cardiomyopathy (RVPIC).

Concerning RVPIC instrumental diagnostic criteria, most studies used an ejection fraction of either $\leq 40 \%$ or $50 \%$, often coupled with an absolute drop of at least $5 \%$ to $10 \%$, to identify approximately $10 \%$ to $20 \%$ of individuals with normal LVEF at baseline (in the setting of high burden RV pacing.)

As for clinical criteria, instead, some studies have addressed heart failure (HF) symptoms, HF hospitalizations, and new onset atrial fibrillation (AF) to fully characterize the disorder. Although RVPIC primarily occurs in the setting of high-burden RV pacing without alternative causes, RV pacing can also worsen preexisting LV dysfunction and may be even more detrimental in the setting of already impaired ejection fraction $[28,29]$. Furthermore, individual susceptibility to RVPIC likely varies significantly and the cumulative risk of the patient's comorbidities is still to be investigated.

The MOST trial identified the cumulative percentage ventricular pacing (Cum\%VP) as a strong predictor of AF and HF hospitalizations in both DDD and VVI pacing groups. Being the burden of ventricular pacing greater in DDD rather than VVI recipients $(90 \%$ vs. $58 \%$ ), RVPIC appears as the trade-off for AV synchrony gained with DDD pacing. Indeed, in the UK-PACE trial, the AV delay in DDD pacemakers was shortened to achieve greater than $90 \%$ ventricular pacing as in the VVI pacemakers. In this setting, a too short AV delay hinders preload (Figure 2) and makes DDD pacing just comparable to a VVI. Indeed, DDD pacing mode with a functionally "short" paced AV interval due to interatrial conduction delay has a pulmonary venous flow pattern similar to VVI pacing [30]. The UK-PACE trial probably suffered this problem because of the short-programmed AV delays (120-150 ms) causing indeed a non-physiologic preload, also in the DDD group, especially at the LRL, owing to delayed left atrial activation due to AP (Figures 1 and 2) [26]. In the MOST trial, the lowest risks of $\mathrm{HF}$ and AF were observed in patients randomized to DDD but with a very low Cum\%VP (no RVPIC) [31]. The negative effects of unnecessary atrial and RVA (Right Ventricular Apical) pacing on LV function were emphasized in the DAVID (Dual Chamber and VVI Implantable Defibrillator) trial, which tested DDD/R pacing at a lower rate of 70 beats against ventricular-only backup pacing (VVI, 40 beats $/ \mathrm{min}$ ) on a composite end point of time to death or first HF hospitalization. The study was prematurely and unexpectedly terminated because of an excess of HF and deaths in the DDD/R arm [28]. 
As in the MOST trial, \% RV pacing was associated with the composite endpoint of death or HF hospitalization, while DDD/R patients with a low Cum\%VP (defined as $<40 \%$ ) had similar or better outcomes compared to the VVI backup group [32]. A relationship between Cum\%VP and HF, ventricular arrhythmias, and death was proved in the MADIT (Multi-center Autonomic Defibrillator Implantation Trial) II trial [29]. The MADIT II trial analysis also shows that RV pacing is associated to a significant increase of long-term mortality. During the extended follow-up, patients with Cum $\% \mathrm{VP}>50 \%$ had an increase in mortality resembling that of non-ICD patients at 8 years ( $56 \%$ and $55 \%$, respectively). This increase in mortality rate occurred $3-5$ years after the implant, RVPIC transitioning form the asymptomatic stage to overt HF [33,34].

A CTOPP sub-analysis confirmed the advantage of AV synchrony in patients nearly dependent on ventricular stimulation at follow-up, while those only seldom in need of stimulation to prevent intermittent bradycardia/asystole did well with VVI pacing (very low Cum\%VP, lower risk to develop RVPIC) [35].

These trials suggest that maintenance of AV coupling is superior to VVI pacing the more patients are dependent on ventricular stimulation, although RVA pacing can cause RVPIC in a minority. This led to different strategies to maintain normal ventricular activation via the His-Purkinje system: (1) development of algorithms to minimize ventricular pacing in those with only sporadic AVB; (2) direct stimulation of the His bundle in those requiring frequent $\mathrm{RV}$ pacing.

\subsubsection{Minimization of Ventricular Pacing}

The SAVE PACE (Search AV Extension and Managed Ventricular Pacing for Promoting Atrioventricular Conduction) trial proved that RV pacing minimization decreases persistent AF compared to standard DDD pacing in patients with SSS [36]. Several other studies with different algorithms for RV pacing minimization enrolled also permanent and intermittent AVB patients, but were unable to convincingly confirm clinical superiority of RV pacing minimization to conventional DDD/DDDR pacing [37-40].

Moreover, the DANPACE (Danish Multicentre Randomized Trial on Single Lead Atrial vs. Dual Chamber Pacing in Sick Sinus Syndrome) study, did not report any AF reduction by AAI/R (no ventricular pacing at all) compared to DDD/R pacing in SND patients, when an upper boundary of PR interval as $260 \mathrm{~ms}$ was accepted for enrolment: new-onset AF was related to prolonged AV interval rather than to Cum \%VP. The disappointing results of these studies based on minimization of ventricular stimulation focused the attention on the AV delay. A long PR is not rare in the general population and is highly prevalent in SND and paroxysmal AVB patients [41,42]. Delayed AV conduction was independently associated to AF rates, HF and in some cases to all-cause mortality in community studies and in specific populations, such as hypertensive patients and those with chronic coronary syndrome [43-45]. Nevertheless, according to current guidelines, permanent pacing may be considered only for patients with persistent symptoms similar to those of pacemaker syndrome attributable to first-degree AVB (PR interval > $300 \mathrm{~ms}$ ) (class IIa recommendation with level of evidence C) [1].

Thus, awareness of the key role of prolonged AV conduction has emerged: how long is it acceptable for the PR interval to avoid the detrimental effect of RVA stimulation? What are the risks of a too short AV delay? The paced AV delay interval and AF rate seem to follow a U-shaped relationship, where the optimal range needs to be patient-tailored [46]. Pacing settings (LRL, AV delay) that create an interatrial conduction longer than the AV interval shall be avoided [47].

The AV delay detrimental effect becomes more complicated when applied in HF patients. In 1030 ICD recipients without symptomatic bradycardia, patients were randomized to atrial pacing with ventricular backup at $60 \mathrm{bpm}$ or ventricular backup pacing at $40 \mathrm{bpm}$. An exploratory analysis revealed a reduction of HF hospitalization rates in patients treated with $\mathrm{AV}$ resynchronization and a PR interval $\geq 230 \mathrm{~ms}$ at baseline [48]. These results were confirmed by a subanalysis of the MINERVA (Minimize Right Ventricular Pacing to Prevent 
Atrial Fibrillation and Heart Failure) trial, in which 1166 patients were randomized to conventional DDDR, MVP, or atrial anti-tachycardia pacing plus MVP. The patient cohort was divided in subgroups, according to short PR $(<180 \mathrm{~ms})$ and long PR $(\geq 180 \mathrm{~ms})$. The PR interval was found to significantly interact with pacing mode for AF incidence: persistent AF incidence was lower in the short PR group treated by right ventricular pacing minimization and in the long PR group treated by standard dual-chamber pacing. This observation suggested that intrinsic PR interval may be used as a selection criterion for tailoring the optimal pacing mode [49].

In this scenario, cardiac resynchronization therapy (CRT) represents the most complete and complex integration of knowledge on the electrical disorganization associated with HF. CRT aims to restore atrioventricular and inter-/intra-ventricular synchrony in HF patients with a wide QRS complex. The beneficial effect of CRT in patients with left bundle block (LBBB) is well established, targeting mainly ventricular resynchronization. More challenging and controversial is to understand the effect of CRT in HF patients with wide QRS complex but no LBBB, or narrow QRS and first-degree AVB. The sub-analysis of COMPANION (Comparison of Medical Therapy, Pacing and Defibrillation in Heart Failure) and MADIT-CRT showed that all-cause mortality and HF hospitalization were decreased by CRT in patients with a long PR interval at baseline $(>230 \mathrm{~ms})$, irrespective of the bundle branch block pattern [50,51]. A CARE-HF (Cardiac ResynchronizationHeart Failure) subanalysis reported that a long PR interval at baseline was predictive of unfavorable outcome, and suggested that shortening the PR interval was a stronger predictor of CRT response than shortening the QRS duration [52]. The role of AV synchrony in CRT patients is highlighted even in the subset without CRT indication, as in in the RethinQ (Resynchronization Therapy in Narrow QRS) trial. This study found no benefit of CRT pacing in HF patients with $<35 \% \mathrm{EF}$, narrow QRS $(<130 \mathrm{~ms})$, New York Heart Association (NYHA) class III, and echocardiographically-detected LV dyssynchrony. By stratifying the population on PR interval (cut off $180 \mathrm{~ms}$ ), there was a statistically significant improvement in $\mathrm{VO} 2$ max and $\mathrm{EF}$ after 6 months of CRT in patients with a long intrinsic PR [53].

\subsubsection{The Tradeoff between RV Pacing Minimization and Suboptimal AV Coupling}

The recently published REAL-CRT (Biventricular Pacing in Prolonged Atrioventricular Interval) pilot study offers a new insight on the debated strategy to spare RV pacing or maintain AV synchrony. In this study, 82 patients with a $>35 \% \mathrm{EF}$, indication for pacing and PR interval $\geq 220 \mathrm{~ms}$ were randomly assigned to CRT or conventional dual-chamber pacing with algorithms for right ventricular pacing avoidance (DDD-VPA). At 12 months, cardiac resynchronization therapy proved superior to DDD-VPA in terms of new-onset AF and better diastolic function (echocardiographic evaluation of $\mathrm{E} / \mathrm{A}$ ratio, $\mathrm{E}$ wave deceleration time and atrial volume). The VPA pacing-minimization strategy, which trades-off AV synchrony to preserve inter-/intraventricular synchrony, seems to be detrimental [54].

In conclusion, conventional atrioventricular pacing entails a compromise between minimization of ventricular stimulation (tradeoff: untailored AV interval with suboptimal ventricular preload and functional mitral regurgitation) and RVPIC to ensure AV coupling.

A theoretically physiologic solution at no compromise is represented by AV and inter/intraventricular resynchronization via direct stimulation of the conduction system (CS).

\section{Conduction System Pacing}

Indirect evidence from large clinical trials [27] points to RVPIC as a possible mechanism of $\mathrm{LV}$ dysfunction in recipients of $\mathrm{AV}$ sequential pacing, this deleterious effect being more prevalent in patients with mild to moderate LV dysfunction prior to pacemaker implantation, or with a $>160 \mathrm{~ms}$ paced QRS, and with increased ventricular stimulation percentage ( $>20 \%$ of time) [55]. Alternative RV pacing sites, such as the outflow tract or septal pacing, have not shown clinical benefit compared to RVA pacing either in the 
setting of bradycardia treatment or of CRT, thus prompting more physiologic ventricular activation [56,57].

CRT has been advocated as an effective treatment of RVPIC, but is largely underused, expensive, and technically challenging in several cases. Moreover, it dictates redundancy by implantation of three endocardial leads in many patients. An approach based on CRT to all patients with advanced AVB without left bundle branch block (LBBB) would unnecessarily cause ventricular dyssynchrony in many patients, as reported by Ploux et al. [58]. In patients with advanced first or second-third degree AVB, and a normal or $<130 \mathrm{~ms}$ QRS duration, CRT increases rather than decreases intra- and inter-ventricular activation time. In this perspective, the mortality data of the MADIT-CRT non-LBBB group [59] and of the Echo CRT trial [60] are not surprising. The prolongation of ventricular activation time due to biventricular stimulation in patients with narrow QRS may partially limit the benefit observed in non-LBBB patients with a long baseline PR interval $>230 \mathrm{~ms}$ observed in MADIT-CRT [50]. These premises warrant the effort to achieve a higher degree of atrioventricular and inter-intraventricular synchrony when treating brady-arrhythmias, beyond biventricular stimulation. In this scenario, conduction system pacing (CSP, meaning His bundle and left/right branches) offers a unique possibility to restore normal cardiac activation. While being increasingly adopted, CSP has yet to prove its efficacy in randomized trials.

Owing to the variable intertwining of the His-Purkinje with myocardial fibers [61], CSP can be selective (the pacing stimulus captures the CS only), or nonselective His Bundle Pacing (NS-HBP), where fusion of the CS and of the adjacent ventricular myocardium occurs. Clinical superiority of the former over the latter is uncertain at this stage [62], although nonselective CSP may yield some technical advantages.

3.1. What Do We Already Know? Several Studies Have Shown the Feasibility, Safety, and Positive Clinical Outcomes of His Bundle Pacing (HBP) Compared with Customary RV Apical Pacing

A recent meta-analysis of single-center studies has shown that HBP is feasible with acceptable pacing thresholds (average threshold $1.71 \mathrm{~V}(95 \%$ CI 1.42-2.01 V), most often reported at a pulse width of $0.5-1 \mathrm{~ms}$ ), which were stable at chronic follow-up, and a low rate of complications in clinical practice [55].

In a multicenter experience, the upgrade to HBP after a mean of 6 years of RV apical pacing significantly decreased QRS duration and improved ventricular function, reversing RVPIC [63]. In a direct comparison with RV apical pacing, HBP showed better clinical outcomes: the primary outcome (death, HF hospitalizations and upgrade to biventricular pacing (BiVP) was reduced significantly ( $25 \%$ during HBP vs. $32 \%$ during RVA, $p=0.02$, $25 \%$ vs. $36 \%$ in patients with VP $>20 \%, p=0.02$ ). A significant improvement of LV function occurred, mostly pronounced in patients with HF [64].

Small studies show HBP as an intriguing alternative in CRT candidates, proving to be effective and safe in implementing CRT in CRT-indicated patients [65-69]. A crossover study by Lustgarten et al. [70] compared NS-HBP with CRT in such patients: a Y-adapter connected both HB and LV leads to the LV port. The authors were able to correct QRS duration in $72 \%$ of cases. Clinical and echocardiographic responses were similar to those of BIV patients, suggesting that NS-HBP was at least as effective as CRT. The 6-months LVEF improved from $26 \%$ to $32 \%$ and $31 \%$ respectively in NS-HBP and conventional CRT, while functional outcomes were similar [69]. Right Bundle Branch Block (RBBB) patients have suboptimal response to CRT [71]: HBP seems to convey the same clinical advantage as true CRT for LBBB patients [72].

Though improved ventricular activation by HBP seems to enhance mechanical resynchronization $[70,73]$, technical issues in term of implant success rate, stability of the pacing capture and of conduction distally to the His bundle, along follow-up are key points for the planning of a large randomized trial of HBP vs. conventional CRT. 


\subsection{Which Possible Indications for CSP?}

The conduction system is an anatomical-functional continuum that offers the possibility to treat conduction disorders at different levels. HBP may be considered in two populations: those with AV nodal disease (Figure 3) and those with infra-Hisian disease (Figure 4).

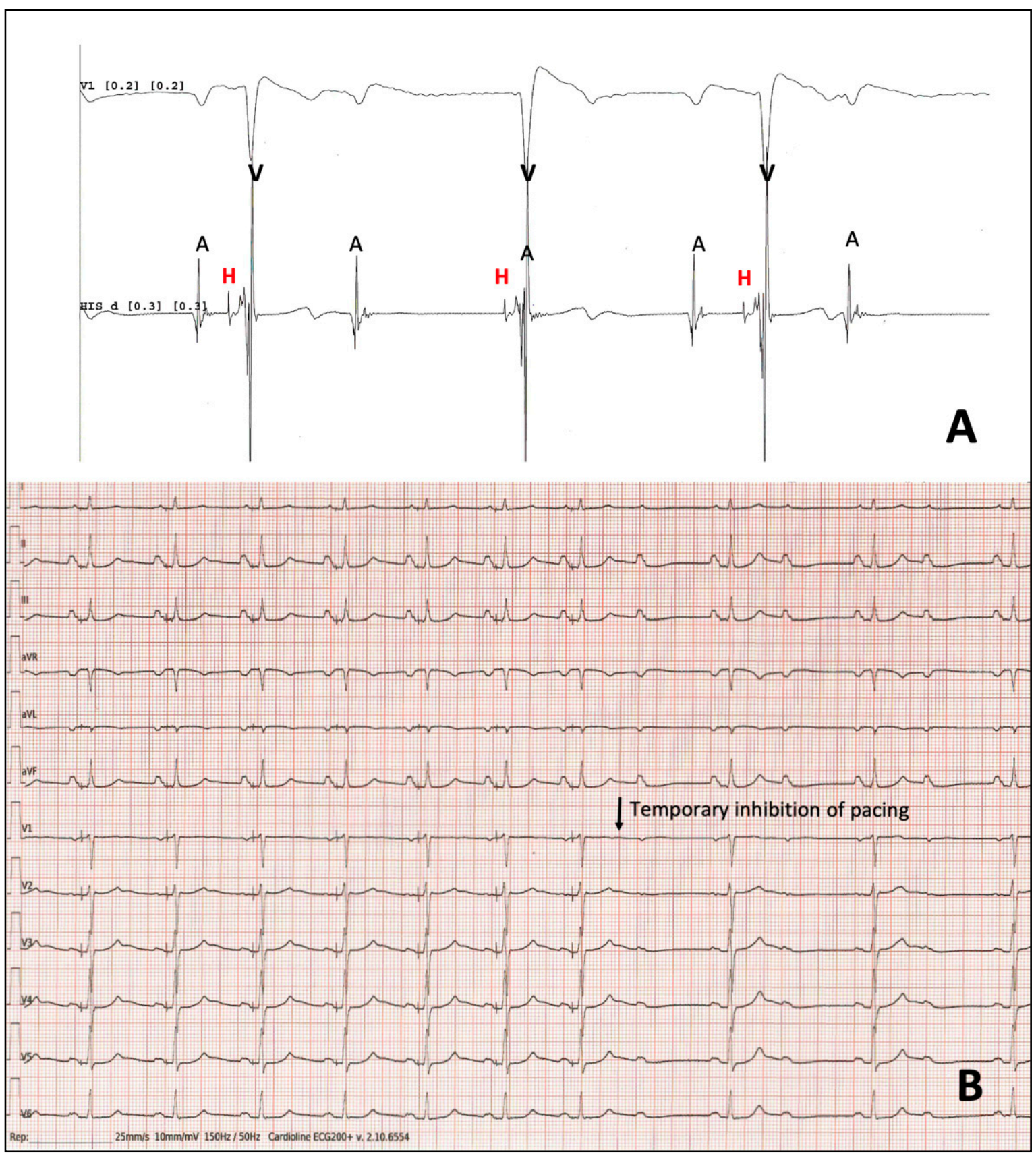

Figure 3. Abbreviations: $\mathrm{A}=$ atrial activation; $\mathrm{H}=\mathrm{His}$ bundle potential; $\mathrm{V}=$ ventricular activation. $\mathrm{AVB}=\mathrm{Atrioventricular}$ block. Panel A: AVB at nodal level: no $\mathrm{H}$ following A. The A-H interval in unpredictable, while the $\mathrm{H}-\mathrm{V}$ interval is stable and reproducible. Panel B: pacemaker implantation with selective His bundle pacing. Note the isoelectric stimulus-QRS interval equal to the $\mathrm{H}-\mathrm{V}$ interval in panel A (50 ms). Upon temporary inhibition of pacing, 2nd AV block with the same QRS morphology as the paced QRS is observed. 


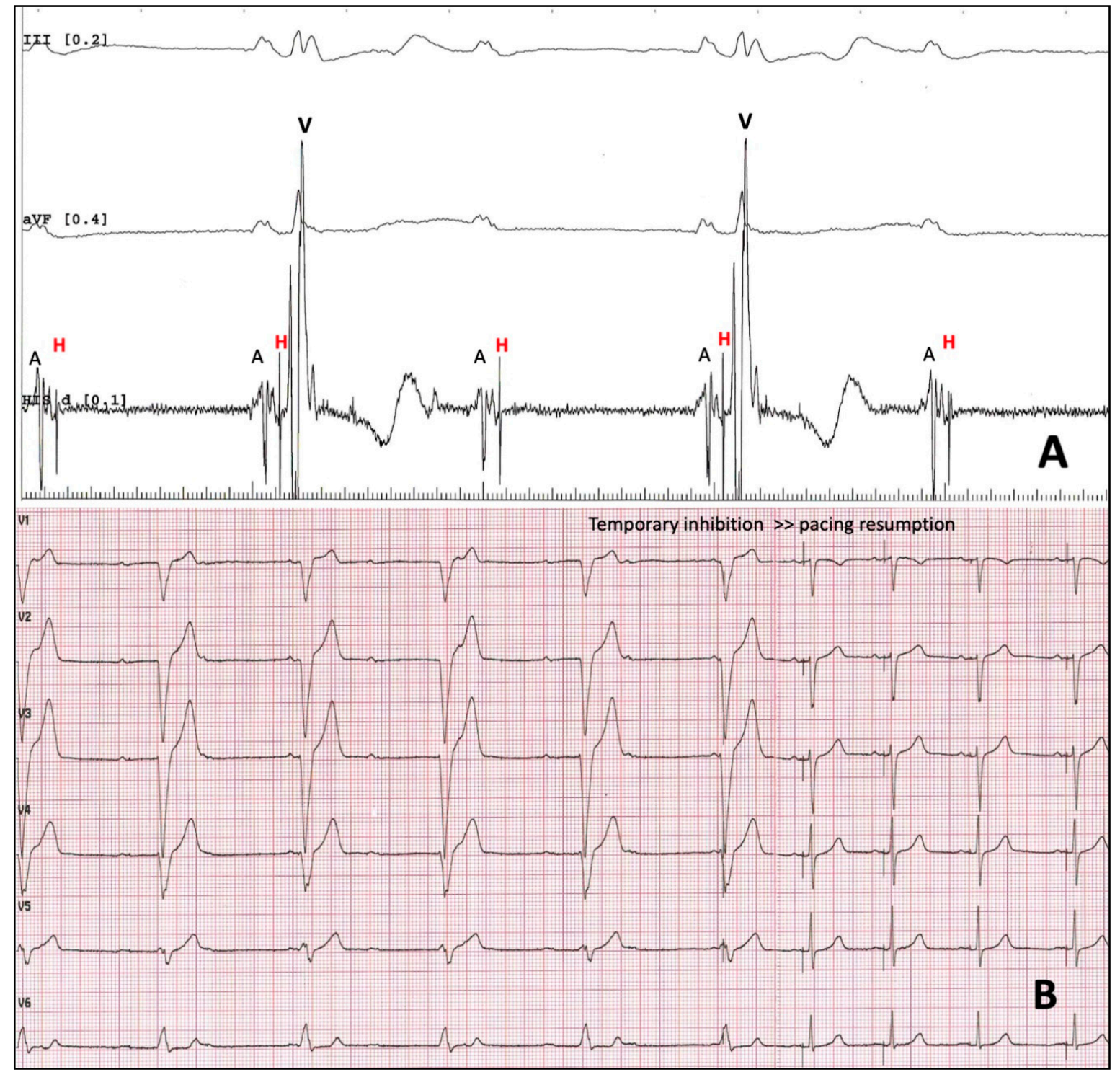

Figure 4. Abbreviations: $\mathrm{A}=$ atrial activation; $\mathrm{H}=\mathrm{His}$ bundle potential; $\mathrm{V}=$ ventricular activation. $\mathrm{AVB}=\mathrm{Atrioventricular}$ block. Panel A: AVB at the His bundle level: no V following H. The A-H interval is stable and reproducible, while failure of conduction from $\mathrm{H}$ to the ventricle occurs. Panel B: after pacemaker implantation with selective His bundle pacing distal to the site of block, intrinsic rhythm shows complete AVB with a broad escape QRS. Upon pacing resumption, capture of the His bundle elicits stimulation of the entire conduction system: note the isoelectric stimulus-QRS interval equal to $50 \mathrm{~ms}$ and the appearance of a normal, narrow, paced QRS.

In both groups, patients with a coexistent bundle branch block (BBB) can also receive $\mathrm{BBB}$ correction and, thus, complete synchronization (Figure 5), while in those without BBB, HBP simply aims to avoid further desynchronization. The true difference in these two scenarios is the challenge to reach a pacing site distal to the site of block in the latter, to ensure consistent capture of the conduction system at long term follow-up with only minimal excitation of the surrounding muscle, resulting in NS-HBP [74]. The need of a back-up ventricular pacing lead is also dependent on a preserved His-ventricular conduction distal to the site of pacing, which can be tested during implantation by rapid HBP pacing [74]. For both groups we can consider the following indications:

- Brady-arrhythmia therapy, including SND with 1st, 2nd and 3rd-degree AVB;

- "Ablate and pace" strategy for AF; 
- Cardiac resynchronization therapy in patients with HF and systolic dysfunction, by restoring AV synchrony in those with AVB first and/or BBB, either right or left.

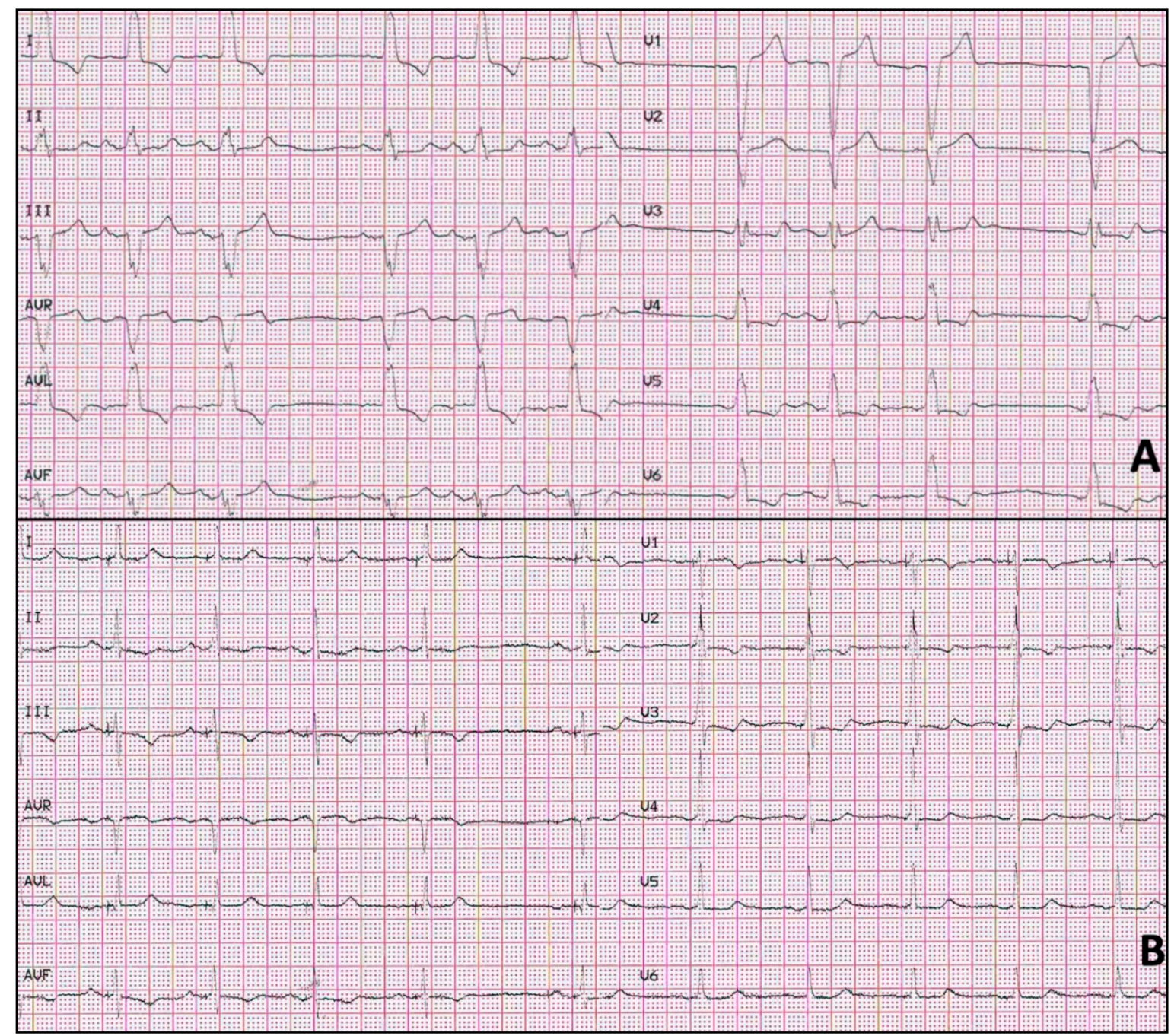

Figure 5. Panel A: patient with moderate aortic valve disease (LVEF $=48 \%$ ) and occasional near-syncopal sinoatrial blocks (5 s), 1st-degree AVB, and left bundle branch block (LBBB). Panel B: pacemaker implantation with selective His bundle pacing and complete LBBB correction. Note the isoelectric stimulus-QRS interval equal to $40 \mathrm{~ms}$. The fifth beat exhibits atrial stimulation with a $\mathrm{P}$ wave similar to the intrinsic one.

In the CRT setting, a particular scenario is failure to deliver optimal CRT for any reason: failure to access the coronary sinus, inadequate coronary vein anatomy to reach the target site, high pacing threshold, or delayed electrical activation from the LV pacing site, leading to an increased LV activation time. In these clinical scenarios, HBP offers a viable solution to CRT-delivery failure, but is associated with several limitations, such as: high capture thresholds with risk of non-capture at follow-up, low R-wave amplitudes, and failure to correct BBB. Indeed, the recently published His-SYNC trial showed lower success rates with $\mathrm{HBP}$ due to a larger number of patients with nonspecific intraventricular conduction defects and high LBBB correction thresholds [75]. To overcome the challenges of HBP in patients with infra-Hisian block, or in CRT-indicated patients in whom LBBB correction is not successful, CSP has been extended to stimulation of the left bundle branch area. LBBAP (left bundle branch area pacing) is a recent innovation aimed at pacing the conduction system beyond the site of conduction block in the majority of patients with HisPurkinje conduction disease. LBBAP lead, by placement in the deep septal myocardium, 
offers very low capture thresholds, high R-wave amplitudes, and the ability to bypass conduction blocks in the distal His bundle or proximal left bundle. LBBAP is feasible in the majority of patients and is associated with low and stable capture threshold at mid-term follow-up [76,77]; in a study of non-ischemic cardiomyopathy patients, Huang et al. [78] showed that LBBAP thresholds were $0.5 \pm 0.15 \mathrm{~V} / 0.5 \mathrm{~ms}$, and substantially stable at 1-year follow-up. LBBAP was feasible and safe, with clinical outcomes at 1 year similar to those observed with conventional CRT.

In patients with advanced cardiomyopathy and intraventricular conduction delay (IVCD) and/or BBB and variable extent of LV scarring, the use of HBP remains uncertain. In about $10-30 \%$ of patients, LBBB may not be correctable by permanent HBP [79]; thus, residual intraventricular conduction delay due to scar or peripheral conduction disease may persist. In these cases, more complete resynchronization can be achieved by CSP together with sequential LV pacing in peripheral myocardial areas lately activated (His Optimized CRT, HOT-CRT). A small observational series of patients with advanced HF showed QRS narrowing and reverse LV remodeling rates by HOT-CRT superior to those reported in CRT studies [77]. Whether this translates into additional hemodynamic and clinical benefits needs to be proven in controlled studies.

\section{Leadless Cardiac Stimulation: Another Step into the Future?}

Leadless stimulation concept dates to the middle seventies, to overcome the risks of device surgery. This aspect is pivotal in frail patients and in young patients who face multiple surgeries in lifetime. Freedom from long-term lead related issues and cosmetic needs are additional advantages.

The first VVIR leadless systems (Nanostim Leadless Cardiac Pacemaker, St. Jude Medical; Micra Transcatheter Pacing system, Medtronic) entered clinical practice in a view to avoid short-term (incidence 8-12\%) pacemaker complications: pneumothorax, cardiac perforation, upper extremity deep vein thrombosis, lead dislodgement, pocket hematomas, and surgical wound issues $[80,81]$. Long-term complications include central vein obstruction, endocarditis, lead failure, tricuspid valve regurgitation, and pocket erosion or infection, and are quite rare in VVIR recipients $(0.2-2.4 \%)[82,83]$.

The first human trial of leadless pacing [84] enrolled 33 patients implanted with a Nanostim device (Table 1). Aside one cardiac perforation and tamponade, the complication free rate at 90 days was $94 \%$ with stable electrical performance and no device complications at three months. The LEADLESS II trial [85] enrolled 526 patients in three countries (Table 1) with a successful implant rate of $96 \%$, a $6.7 \%$ rate of major adverse effects had been observed at six months (1.3\% perforation; $1.3 \%$ elevated pacing threshold requiring reintervention, $1.2 \%$ of vascular complications and $1.7 \%$ of device dislodgement). Regretfully, significant serious events and a device battery recall led to termination of Nanostim implantation, with several indications to pacemaker retrieval. Among 1423 cases of Nanostim implantation worldwide, there were 34 battery failures due to increased battery resistance [86]. In a longterm series of 14 consecutive patients, device failure was higher than $40 \%$ after 3 years [87]. Moreover, the manufacturer halted Nanostim implantation in 2016 with the indication of replacement in pacemaker-dependent patients. Feasibility of implantation of another transvenous or leadless pacemaker, with or without extraction of the previous one, was demonstrated [88]. 
Table 1. Leadless system trials $[84,85,89,90]$.

\begin{tabular}{ccccc}
\hline & Leadless & Leadless II & $\begin{array}{c}\text { Micra Transcatheter } \\
\text { Pacing Trial (IDE) }\end{array}$ & $\begin{array}{c}\text { Micra Post Approval } \\
\text { Registry } \\
\text { (PAR-Ongoing) }\end{array}$ \\
\hline $\begin{array}{c}\text { Enrollment period } \\
\text { (from-to) }\end{array}$ & Dec 2012-April 2013 & Feb 2014-June 2015 & Dec 2013-May 2015 & July 2015-ongoing \\
\hline System & Nanostim & Nanostim & Micra & 725 \\
\hline Population (n) & 33 & 526 & 180 & 795 (intended 1830) \\
\hline Follow-up (days) & 90 & 180 & $99.2 \%$ & 30 (ongoing) \\
\hline Successful implant rate (\%) & $97 \%$ & $95.8 \%$ & $3,4 \%$ & $1.5 \%$ \\
\hline $\begin{array}{c}\text { Acute major complication } \\
\text { rate (\%) }\end{array}$ & $6 \%$ & $6.7 \%$ & \\
\hline
\end{tabular}

The Micra Transcatheter Pacing Trial [89] was an international prospective multicenter study that demonstrated the efficacy and safety of Micra system with a 3.4\% rate of complications at six months in 725 patients ( $1.5 \%$ perforation; $0.7 \%$ vascular complications), the majority of whom with adequate six-month pacing capture threshold (Table 1). The safety results were compared with an historical 2667 patients control cohort who received transvenous pacemakers in a post hoc analysis, with similar results obtained in the propensity-matched analysis. A real-life ongoing analysis [90], reporting around $1.5 \%$ of major complications, seems to confirm the previously reported data. A small study of transvenous VVIR vs. leadless VVIR reported no difference in terms of overall complications [91] (Table 2). A real comparison of transvenous and leadless VVIR pacemakers in adequately trained centers is not available, and it seems that the premises of leadless technology await confirmation in the clinical arena.

Table 2. Complication rate of leadless as compared to transvenous pacemakers $[84,85,89-91]$.

\begin{tabular}{ccc}
\hline & Leadless Pacing Systems & Transvenous Pacing Systems \\
\hline $\begin{array}{c}\text { Total short terms } \\
\text { complications }\end{array}$ & $3.4-4.8 \%$ & $6.4-12 \%$ \\
\hline Pericardial effusion & $0.6-1.5 \%$ & $0.3-1.2 \%$ \\
\hline Cardiac perforation & $1.3-1.5 \%$ & $0.1-0.8 \%$ \\
\hline Access site & $0.7-1.2 \%$ & $1.2-2.2 \%$ \\
\hline High pacing threshold & $0.3-1.3 \%$ & $0.8-1.6 \%$ \\
\hline
\end{tabular}

According to two contemporary registries [92,93], VVIR pacemakers are indicated in around $10 \%$ of pacemaker recipients [1]. As reported by a recent EHRA (European Heart Rhythm Association) survey [94] involving 52 high-volume European centers, anticipated difficult vascular access, history of complicated conventional PM implantation, permanent atrial fibrillation, and an anticipated higher risk of infections were the features that dictated the choice of a leadless pacemaker. Interestingly, the main reason reported for not implanting these devices included limited availability and economic issues, such as lack of reimbursement or high cost of the device. The longevity of leadless batteries is an important aspect: expected life-service is strongly dependent on the effective pacing settings, being estimated as 10 years for Micra [95]. Moreover, the computational work is decreased, and remote monitoring is not available to minimize current drain.

In 2020, both FDA and CE approved Micra AV, a leadless pacing system, which aims to synchronize ventricular stimulation with atrial activity, featuring a VDD software in the same VVIR Micra. This single-chamber VDD is equipped with a 3-axis accelerometer, which enables to detect four blood flow accelerations in the right ventricle corresponding to the heart sounds. The fourth signal (A4) of each cycle represents the atrial contraction (the 
A wave of Doppler trans-mitral flow); thus, triggering ventricular stimulation. Diastolic ventricular filling (or E wave) is recorded as the A3 signal. Feasibility and efficacy of AV synchrony (AVS) delivered by Micra AV in patients with high degree AV block have been demonstrated in acute studies with a downloaded software: MASS (Micra Accelerometer Sensor Sub-Study), MASS2, MARVEL (Micra Atrial Tracking using a Ventricular Accelerometer), and MARVEL2 studies. In the latter, 38/40 patients with variable extent of AVB achieved $\geq 70 \% \mathrm{AV}$ synchronous pacing, defined as the presence of a ventricular paced event within $300 \mathrm{~ms}$ of an intrinsic P wave. MARVEL and MARVEL2 studies showed that stroke volume, assessed with echocardiography, was improved by AVS compared to VVI pacing. In MARVEL2, patients had lower sinus rates in VDD mode than in VVI mode, meaning a decreased sympathetic activity when more physiological-pacing is achieved. However, studies on long-term benefits of Micra AV are lacking [96,97]. Sensing atrial activity via its mechanical counterpart may pose some issues, atrial undersensing being a major concern in several scenarios. In the event of ineffective atrial contraction, no A4 is detected: an E/A > 1.5 is predictive of A4 undersensing. Fusion between A3 and A4 may occur during sinus tachycardia; thus, limiting rate increase and exercise tolerance. Body movement can interfere with A4 sensing, as well as frequent PVCs [98]. Rate smoothing can mitigate transient atrial undersensing: assuming a regular atrial activation, pacing occurs for a brief period also when A4 signal is hampered. This produces a typical variability of the AV delay at 1-lead ECG (Figure 6) In the event of A4 undersensing, the device switches to VVIR mode producing appropriate rate-responsiveness: older patients with AVB typically engage in physical activity for short periods of time, and rate-responsiveness is thought a reasonable compromise.

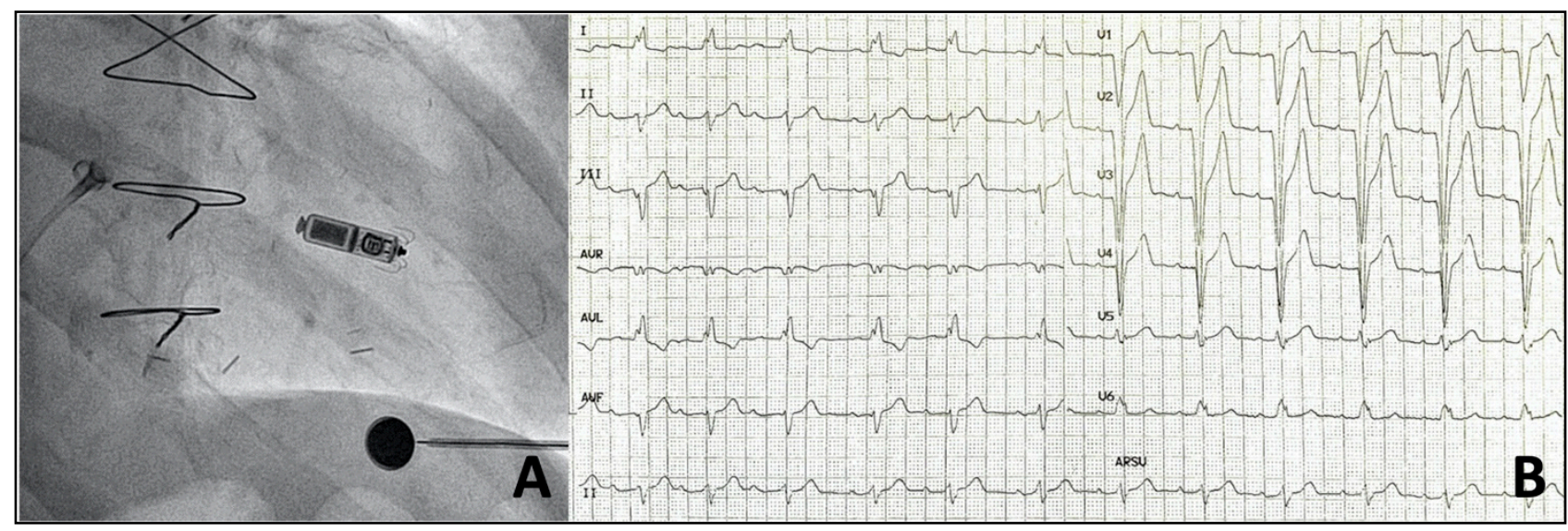

Figure 6. Panel A: Micra AV leadless pacemaker implanted at the mid-septum in a patient with atrioventricular block. Panel B: Micra AV leadless pacemaker. Note that tracking of the P wave occurs with a variable atrioventricular delay within $300 \mathrm{~ms}$ in the first seven beats, owing to incorrect detection of the fourth heart sound.

It is known that right ventricular pacing, with or without AV synchrony, may promote RVPIC [99]. Micra AV aims to transfer AV coupling in the leadless world, but still provides only non-physiologic right ventricular stimulation with unreliable and often non-physiologic AV intervals. Indeed, the electromechanical delay between electrical $\mathrm{P}$ wave and A4 signal may cause long AV intervals (Figure 6), that warn about the incidence of new-onset AF, HF, and mortality. This pitfall is partially mitigated by the intact $\mathrm{AV}$ conduction mode switch algorithm, which periodically checks for intrinsic conduction and reduces unnecessary pacing. Further studies are warranted to evaluate long-term implications of leadless AV pacing on cardiac function.

After a thorough analysis of all different pacing modes, we suggest below a brief guidance to select the most appropriate one based on specific patients' characteristics (Table 3). 
Table 3. Guidance to pacing system selection based on preferential factors.

\begin{tabular}{ccccc}
\hline & $\begin{array}{c}\text { Conventional } \\
\text { TV Pacemaker }\end{array}$ & $\begin{array}{c}\text { Leadless } \\
\text { Pacemaker }\end{array}$ & $\begin{array}{c}\text { Conduction } \\
\text { System Pacing }\end{array}$ & CRT-P \\
\hline $\begin{array}{c}\text { Occluded superior } \\
\text { access to the heart }\end{array}$ & - & +++ & - & - \\
\hline $\begin{array}{c}\text { Superior access to be } \\
\text { preserved }\end{array}$ & - & ++ & - & - \\
\hline $\begin{array}{c}\text { Indwelling TV catheters } \\
\text { Frail patients prone to } \\
\text { bleeding }\end{array}$ & - & ++ & - & - \\
\hline $\begin{array}{c}\text { Previous infection \& } \\
\text { CIED extraction }\end{array}$ & - & ++ & - & - \\
\hline$<20 \%$ Vp expected & + & ++ & + & + \\
\hline Baseline EF <50\% & - & + & + & + \\
\hline Narrow QRS at baseline & - & - & ++ & ++ \\
\hline BBB at baseline & + & - & ++ & ++ \\
\hline History of heart failure & - & - & ++ & ++ \\
\hline $\begin{array}{c}\text { Paced QRS duration }> \\
160 \text { ms }\end{array}$ & - & - & + & + \\
\hline Cost & ++ & + & + & + \\
\hline
\end{tabular}

Legend: $\mathrm{BBB}=$ bundle branch block; CIED = cardiac implantable electronic device; $\mathrm{CRTP}$ = cardiac resynchronization therapy pacemaker; $\mathrm{EF}=$ ejection fraction; $\mathrm{TV}=$ transvenous; $\mathrm{Vp}=$ ventricular pacing. Legend: least appropriate -; appropriate +; very appropriate ++; most appropriate +++.

\section{Conclusions}

The complex interplay of interatrial, atrioventricular and inter-ventricular conduction dictates that restoration of the normal activation along Bachmann bundles, AV node, and His Purkinje network, should be the preferred pacing modality (Figure 7). Convincing evidence of such a pacing strategy awaits confirmation of appropriately designed clinical trials, which stand on the availability of dedicated tools and technology to enable broad application of CSP and leadless pacing in all clinical settings. While these latter are technically successful only in a minority of patients nowadays, specific patient characteristics and therapeutic goals to be achieved are key elements to consider in selecting the most appropriate pacing modality.

In clinical practice, the most physiologic settings are achieved with available technologies in a view to the best possible individualized treatment:

- Avoid unnecessary atrial stimulation to prevent interatrial dyssynchrony and excessive prolongation of the AV interval;

- Avoid unnecessary ventricular stimulation until mild prolongation of the PR interval;

- Treat advanced AV block by His bundle pacing in patients with $<130$ ms QRS duration;

- Correct BBB by CSP at any level or CRT in broad QRS complex patients;

- Apply ventricular stimulation to correct intraventricular conduction delay residual to CSP, or CRT when CSP is not effective/not feasible.

Though the ideal stimulation pattern aims to mimic the normal conduction to restore electro-mechanical coupling in all patients, individualized medicine can dictate different therapeutic choices, depending on the clinical scenario and on the priority of patient needs. 


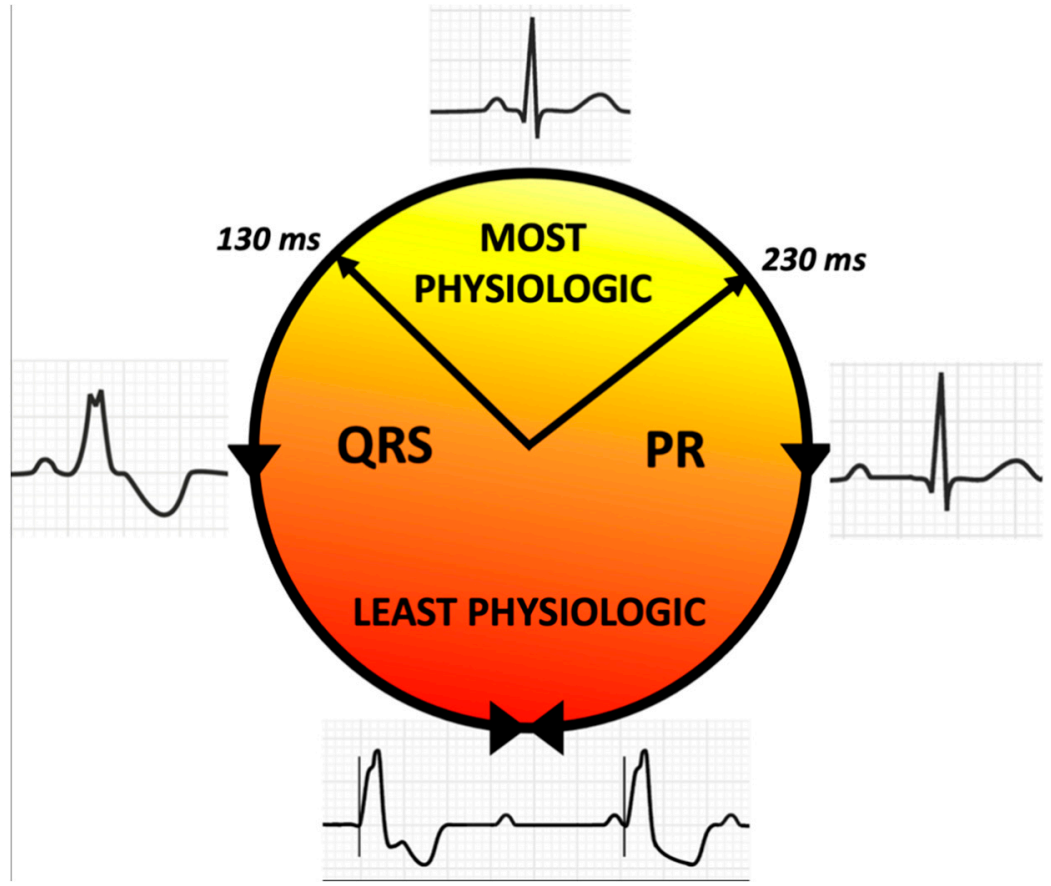

Figure 7. The continuum of physiologic cardiac stimulation as applied in different clinical scenarios according to electrophysiological parameters.

Funding: This research received no external funding.

Conflicts of Interest: Mauro Biffi: educational activity and Speaker's bureau for Biotronik, Boston Scientific, Medtronic, and Zoll. All figures and tables are sourced from authors' clinical cases at Azienda Ospedaliero-Universitaria Sant’Orsola-Malpighi di Bologna.

\section{References}

1. Brignole, M.; Auricchio, A.; Baron-Esquivias, G.; Bordachar, P.; Boriani, G.; Breithardt, O.A.; Cleland, J.; Deharo, J.C.; Delgado, V.; Elliott, P.M.; et al. 2013 ESC Guidelines on cardiac pacing and cardiac resynchronization therapy. Eur. Heart J. 2013, 34, $2281-2329$. [CrossRef] [PubMed]

2. Varma, N.; Ricci, R.P. Telemedicine and cardiac implants: What is the benefit? Eur. Heart J. 2013, 34, 1885-1895. [CrossRef]

3. Zhang, X.H.; Chen, H.; Siu, C.W.; Yiu, K.H.; Chan, W.S.; Lee, K.L.; Chan, H.W.; Lee, S.W.; Fu, G.S.; Lau, C.P.; et al. New-onset heart failure after permanent right ventricular apical pacing in patients with acquired high-grade atrioventricular block and normal left ventricular function. J. Cardiovasc. Electrophysiol. 2008, 19, 136-141. [CrossRef] [PubMed]

4. Proclemer, A.; Zecchin, M.; D'Onofrio, A.; Boriani, G.; Ricci, R.P.; Rebellato, L.; Ghidina, M.; Bianco, G.; Bernardelli, E.; Miconi, A.; et al. The Pacemaker and Implantable Cardioverter-Defibrillator Registry of the Italian Association of Arrhythmology and Cardiac Pacing-Annual report 2018. G. Ital. Cardiol. 2020, 21, 157-169. [CrossRef]

5. Stabile, G.; Senatore, G.; Simone, A.; Turco, P.; Coltorti, F.; Nocerino, P.; Vitale, D.F.; Chiariello, M. Determinants of Efficacy of Atrial Pacing in Preventing Atrial Fibrillation Recurrences. J. Cardiovasc. Electrophysiol. 1999, 10, 2-9. [CrossRef] [PubMed]

6. Bernheim, A.; Ammann, P.; Sticherling, C.; Burger, P.; Schaer, B.; Rocca, H.P.B.-L.; Eckstein, J.; Kiencke, S.; Kaiser, C.; Linka, A.; et al. Right Atrial Pacing Impairs Cardiac Function During Resynchronization Therapy. J. Am. Coll. Cardiol. 2005, 45, $1482-1487$. [CrossRef]

7. Healey, J.S.; Martin, J.L.; Duncan, A.; Connolly, S.J.; Ha, A.H.; Morillo, C.A.; Nair, G.M.; Eikelboom, J.; Divakaramenon, S.; Dokainish, H. Pacemaker-Detected Atrial Fibrillation in Patients with Pacemakers: Prevalence, Predictors, and Current Use of Oral Anticoagulation. Can. J. Cardiol. 2013, 29, 224-228. [CrossRef]

8. Bukari, A.; Wali, E.; Deshmukh, A.; Aziz, Z.; Broman, M.; Beaser, A.; Upadhyay, G.; Nayak, H.; Tung, R.; Ozcan, C. Prevalence and predictors of atrial arrhythmias in patients with sinus node dysfunction and atrial pacing. J. Interv. Card. Electrophysiol. 2018, 53, 365-371. [CrossRef]

9. Benjamin, E.J.; Levy, D.; Vaziri, S.M.; D'Agostino, R.B.; Belanger, A.J.; Wolf, P.A. Independent risk factors for atrial fibrillation in a population-based cohort. The Framingham Heart Study. JAMA 1994, 271, 840-844. [CrossRef] 
10. Sławuta, A.; Kliś, M.; Skoczyński, P.; Bańkowski, T.; Moszczyńska-Stulin, J.; Gajek, J. Bachmann's Bundle Pacing not Only Improves Interatrial Conduction but Also Reduces the Need for Ventricular Pacing. Adv. Clin. Exp. Med. 2016, 25, 845-850. [CrossRef]

11. Verlato, R.; Botto, G.L.; Massa, R.; Amellone, C.; Perucca, A.; Bongiorni, M.G.; Bertaglia, E.; Ziacchi, V.; Piacenti, M.; Del Rosso, A.; et al. Efficacy of Low Interatrial Septum and Right Atrial Appendage Pacing for Prevention of Permanent Atrial Fibrillation in Patients with Sinus Node Disease: Results From the Electrophysiology-Guided Pacing Site Selection (EPASS) Study. Circ. Arrhythmia Electrophysiol. 2011, 4, 844-850. [CrossRef] [PubMed]

12. Bailin, S.J.; Adler, S.; Giudici, M. Prevention of chronic atrial fibrillation by pacing in the region of Bachmann's bundle: Results of a multicenter randomized trial. J. Cardiovasc. Electrophysiol. 2001, 12, 912-917. [CrossRef] [PubMed]

13. Manolis, A.G.; Katsivas, A.G.; Vassilopoulos, C.; Koutsogeorgis, D.; Louvros, N.E. Prevention of atrial fibrillation by inter-atrial septum pacing guided by electrophysiological testing, in patients with delayed interatrial conduction. Europace 2002, 4, 165-174. [CrossRef] [PubMed]

14. Johner, N.; Namdar, M.; Shah, D.C. Intra- and interatrial conduction abnormalities: Hemodynamic and arrhythmic significance. J. Interv. Card. Electrophysiol. 2018, 52, 293-302. [CrossRef] [PubMed]

15. Fontenla, A.; Salguero, R.; Martinez-Ferrer, J.B.; Rodriguez, A.; Alzueta, J.; Garcia, E.; Basterra, N.; Romero, R.; De La Concha, J.F.; Viñolas, X.; et al. Atrial Rate-Responsive Pacing and Incidence of Sustained Atrial Arrhythmias in Patients with Implantable Cardioverter Defibrillators. Pacing Clin. Electrophysiol. 2016, 39, 548-556. [CrossRef]

16. Biffi, M.; D’Onofrio, A.; Pignalberi, C.; Pisanò, E.C.; Iacopino, S.; Curnis, A.; Senatore, G.; Capucci, A.; Della Bella, P.; Calvi, V.; et al. Rate-responsive pacing and atrial high rate episodes in cardiac resynchronization therapy patients: Is low heart rate the key? Clin. Cardiol. 2019, 42, 820-828. [CrossRef]

17. Liao, J.-N.; Chao, T.-F.; Tuan, T.-C.; Kong, C.-W.; Chen, S.-A. Long-term outcome in patients receiving permanent pacemaker implantation for atrioventricular block. Medicine 2016, 95, e4668. [CrossRef]

18. Biffi, M.; Massaro, G.; Candelora, A.; Angeletti, A.; Valzania, C.; Martignani, C.; Grassini, D.; Diemberger, I.; Ziacchi, M. Less is more: Can we achieve cardiac resynchronization with 2 leads only? Int. J. Cardiol. 2017, 249, 184-190. [CrossRef]

19. Ziacchi, M.; Palmisano, P.; Biffi, M.; Ricci, R.P.; Landolina, M.; Zoni-Berisso, M.; Occhetta, E.; Maglia, G.; Botto, G.; Padeletti, L.; et al. Clinically oriented device programming in bradycardia patients: Part 1 (sinus node disease). Proposals from AIAC (Italian association of arrhythmology and cardiac pacing). J. Cardiovasc. Med. 2018, 19, 161-169. [CrossRef]

20. Barold, S.S.; Ilercil, A.; Herweg, B. Echocardiographic optimization of the atrioventricular and interventricular intervals during cardiac resynchronization. EP Eur. 2008, 10 (Suppl. 3), iii88-iii95. [CrossRef]

21. Ishikawa, T.; Kimura, K.; Miyazaki, N.; Tochikubo, O.; Usui, T.; Kashiwagi, M.; Ishii, M. Diastolic mitral regurgitation in patients with first-degree atrioventricular block. Pacing Clin. Electrophysiol. 1992, 15, 1927-1931. [CrossRef] [PubMed]

22. Ishikawa, T.; Sumita, S.; Kimura, K.; Kuji, N.; Nakayama, R.; Nagura, T.; Miyazaki, N.; Tochikubo, O.; Usui, T.; Kashiwagi, M.; et al. Critical PQ Interval for the Appearance of Diastolic Mitral Regurgitation and Optimal PQ Interval in Patients Implanted with DDD Pacemakers. Pacing Clin. Electrophysiol. 1994, 17, 1989-1994. [CrossRef] [PubMed]

23. Connolly, S.J.; Kerr, C.R.; Gent, M.; Roberts, R.S.; Yusuf, S.; Gillis, A.M.; Sami, M.H.; Talajic, M.; Tang, A.S.L.; Klein, G.J.; et al. Effects of Physiologic Pacing versus Ventricular Pacing on the Risk of Stroke and Death Due to Cardiovascular Causes. New Engl. J. Med. 2000, 342, 1385-1391. [CrossRef] [PubMed]

24. Kerr, C.R.; Connolly, S.J.; Abdollah, H.; Roberts, R.S.; Gent, M.; Yusuf, S.; Gillis, A.M.; Tang, A.S.L.; Talajic, M.; Klein, G.J.; et al. Canadian Trial of Physiological Pacing. Circulation 2004, 109, 357-362. [CrossRef]

25. Lamas, G.A.; Lee, K.L.; Sweeney, M.O.; Silverman, R.; Leon, A.; Yee, R.; Marinchak, R.A.; Flaker, G.; Schron, E.; Orav, E.J.; et al. Ventricular Pacing or Dual-Chamber Pacing for Sinus-Node Dysfunction. New Engl. J. Med. 2002, 346, 1854-1862. [CrossRef]

26. Toff, W.D.; Camm, A.J.; Skehan, J.D. Single-Chamber versus Dual-Chamber Pacing for High-Grade Atrioventricular Block. New Engl. J. Med. 2005, 353, 145-155. [CrossRef]

27. Healey, J.S.; Toff, W.D.; Lamas, G.A.; Andersen, H.R.; Thorpe, K.E.; Ellenbogen, K.A.; Lee, K.L.; Skene, A.M.; Schron, E.B.; Skehan, J.D.; et al. Cardiovascular outcomes with atrial-based pacing compared with ventricular pacing: Meta-analysis of randomized trials, using individual patient data. Circulation 2006, 114, 11-17. [CrossRef]

28. The DAVID Trial Investigators. Dual-Chamber Pacing or Ventricular Backup Pacing in Patients with an Implantable Defibrillator. JAMA 2002, 288, 3115-3123. [CrossRef]

29. Steinberg, J.S.; Fischer, A.; Wang, P.; Schuger, C.; Daubert, J.; Mcnitt, S.; Andrews, M.; Brown, M.; Hall, W.J.; Zareba, W.; et al. The clinical implications of cumulative right ventricular pacing in the multicenter automatic defibrillator trial II. J. Cardiovasc. Electrophysiol. 2005, 16, 359-365. [CrossRef]

30. Stierle, U.; Krüger, D.; Mitusch, R.; Potratz, J.; Taubert, G.; Sheikhzadeh, A. Adverse Pacemaker Hemodynamics Evaluated by Pulmonary Venous Flow Monitoring. Pacing Clin. Electrophysiol. 1995, 18, 2028-2034. [CrossRef]

31. Sweeney, M.O.; Hellkamp, A.S.; Ellenbogen, K.A.; Greenspon, A.J.; Freedman, R.A.; Lee, K.L.; Lamas, G.A. Adverse effect of ventricular pacing on heart failure and atrial fibrillation among patients with normal baseline QRS duration in a clinical trial of pacemaker therapy for sinus node dysfunction. Circulation 2003, 107, 2932-2937. [CrossRef] [PubMed]

32. Sharma, A.D.; Rizo-Patron, C.; Hallstrom, A.P.; O’Neill, G.P.; Rothbart, S.; Martins, J.B.; Roelke, M.; Steinberg, J.S.; Greene, H.L. Percent right ventricular pacing predicts outcomes in the DAVID trial. Heart Rhythm 2005, 2, 830-834. [CrossRef] [PubMed] 
33. Barsheshet, A.; Moss, A.J.; McNitt, S.; Jons, C.; Glikson, M.; Klein, H.U.; Huang, D.T.; Steinberg, J.S.; Brown, M.W.; Zareba, W.; et al. Long-term implications of cumulative right ventricular pacing among patients with an implantable cardioverter-defibrillator. Heart Rhythm 2011, 8, 212-218. [CrossRef] [PubMed]

34. Sweeney, M.O.; Prinzen, F.W. Ventricular pump function and pacing: Physiological and clinical integration. Circ. Arrhythmia Electrophysiol. 2008, 1, 127-139. [CrossRef]

35. Tang, A.S.L.; Roberts, R.S.; Kerr, C.; Gillis, A.M.; Green, M.S.; Talajic, M.; Yusuf, S.; Abdollah, H.; Gent, M.; Connolly, S.J. Relationship between pacemaker dependency and the effect of pacing mode on cardiovascular outcomes. Circulation 2001, 103, 3081-3085. [CrossRef]

36. Sweeney, M.O.; Bank, A.J.; Nsah, E.; Koullick, M.; Zeng, Q.C.; Hettrick, D.; Sheldon, T.; Lamas, G.A. Minimizing Ventricular Pacing to Reduce Atrial Fibrillation in Sinus-Node Disease. N. Engl. J. Med. 2007, 357, 1000-1008. [CrossRef]

37. Boriani, G.; Tukkie, R.; Manolis, A.S.; Mont, L.; Pürerfellner, H.; Santini, M.; Inama, G.; Serra, P.; De Sousa, J.; Botto, G.L.; et al. Atrial antitachycardia pacing and managed ventricular pacing in bradycardia patients with paroxysmal or persistent atrial tachyarrhythmias: The MINERVA randomized multicentre international trial. Eur. Heart J. 2014, 35, 2352-2362. [CrossRef]

38. Stockburger, M.; Boveda, S.; Moreno, J.; Da Costa, A.; Hatala, R.; Brachmann, J.; Butter, C.; Seara, J.G.; Rolando, M.; Defaye, P. Long-term clinical effects of ventricular pacing reduction with a changeover mode to minimize ventricular pacing in a general pacemaker population. Eur. Heart J. 2015, 36, 151-157. [CrossRef]

39. Thibault, B.; Ducharme, A.; Baranchuk, A.; Dubuc, M.; Dyrda, K.; Guerra, P.G.; Macle, L.; Mondésert, B.; Rivard, L.; Roy, D.; et al. Very Low Ventricular Pacing Rates Can Be Achieved Safely in a Heterogeneous Pacemaker Population and Provide Clinical Benefits: The CANadian Multi-Centre Randomised Study-Spontaneous AtrioVEntricular Conduction pReservation (CAN-SAVE R) Trial. J. Am. Heart Assoc. 2015, 4, e001983. [CrossRef]

40. Shurrab, M.; Healey, J.S.; Haj-Yahia, S.; Kaoutskaia, A.; Boriani, G.; Carrizo, A.; Botto, G.; Newman, D.; Padeletti, L.; Connolly, S.J.; et al. Reduction in unnecessary ventricular pacing fails to affect hard clinical outcomes in patients with preserved left ventricular function: A meta-analysis. Europace 2017, 19, 282-288. [CrossRef]

41. Nikolaidou, T.; Ghosh, J.M.; Clark, A.L. Outcomes Related to First-Degree Atrioventricular Block and Therapeutic Implications in Patients with Heart Failure. JACC Clin. Electrophysiol. 2016, 2, 181-192. [CrossRef] [PubMed]

42. Auricchio, A.; Ellenbogen, K.A. Reducing Ventricular Pacing Frequency in Patients with Atrioventricular Block. Circ. Arrhythmia Electrophysiol. 2016, 9, e004404. [CrossRef]

43. Cheng, S.; Keyes, M.J.; Larson, M.G.; McCabe, E.L.; Newton-Cheh, C.; Levy, D.; Benjamin, E.J.; Vasan, R.S.; Wang, T.J. Longterm Outcomes in Individuals with Prolonged PR Interval or First-Degree Atrioventricular Block. JAMA 2009, 301, 2571-2577. [CrossRef]

44. Uhm, J.-S.; Shim, J.; Wi, J.; Mun, H.-S.; Park, J.; Park, S.-H.; Joung, B.; Pak, H.-N.; Lee, M.-H. First-degree atrioventricular block is associated with advanced atrioventricular block, atrial fibrillation and left ventricular dysfunction in patients with hypertension. J. Hypertens. 2014, 32, 1115-1120. [CrossRef] [PubMed]

45. Crisel, R.K.; Farzaneh-Far, R.; Na, B.; Whooley, M.A. First-degree atrioventricular block is associated with heart failure and death in persons with stable coronary artery disease: Data from the Heart and Soul Study. Eur. Heart J. 2011, 32, 1875-1880. [CrossRef] [PubMed]

46. Gasparini, M.; Birnie, D.; Lemke, B.; Aonuma, K.; Lee, K.L.-F.; Gorcsan, J.; Landolina, M.; Klepfer, R.; Meloni, S.; Cicconelli, M.; et al. Adaptive Cardiac Resynchronization Therapy Reduces Atrial Fibrillation Incidence in Heart Failure Patients with Prolonged AV Conduction. Circ. Arrhythmia Electrophysiol. 2019, 12, e007260. [CrossRef]

47. Eicher, J.C.; Laurent, G.; Mathé, A.; Barthez, O.; Bertaux, G.; Philip, J.L.; Dorian, P.; Wolf, J.E. Atrial dyssynchrony syndrome: An overlooked phenomenon and a potential cause of "diastolic" heart failure. Eur. J. Heart Fail. 2012, 14, 248-258. [CrossRef]

48. Sweeney, M.O.; Ellenbogen, K.A.; Tang, A.S.L.; Whellan, D.; Mortensen, P.T.; Giraldi, F.; Sandler, D.A.; Sherfesee, L.; Sheldon, T. Atrial pacing or ventricular backup-only pacing in implantable cardioverter-defibrillator patients. Heart Rhythm 2010, 7, 15521560. [CrossRef]

49. Boriani, G.; Pieragnoli, P.; Botto, G.L.; Puererfellner, H.; Mont, L.; Ziacchi, M.; Manolis, A.S.; Gulizia, M.; Tukkie, R.; Landolina, M.; et al. Effect of PR interval and pacing mode on persistent atrial fibrillation incidence in dual chamber pacemaker patients: A sub-study of the international randomized MINERVA trial. EP Eur. 2019, 21, 636-644. [CrossRef]

50. Stockburger, M.; Moss, A.J.; Klein, H.U.; Zareba, W.; Goldenberg, I.; Biton, Y.; McNitt, S.; Kutyifa, V. Sustained clinical benefit of cardiac resynchronization therapy in non-LBBB patients with prolonged PR-interval: MADIT-CRT long-term follow-up. Clin. Res. Cardiol. 2016, 105, 944-952. [CrossRef]

51. Lin, J.; Buhr, K.A.; Kipp, R. Effect of PR Interval on Outcomes Following Cardiac Resynchronization Therapy: A Secondary Analysis of the COMPANION Trial. J. Cardiovasc. Electrophysiol. 2017, 28, 185-191. [CrossRef] [PubMed]

52. Gervais, R.; Leclercq, C.; Shankar, A.; Jacobs, S.; Eiskjær, H.; Johannessen, A.; Freemantle, N.; Cleland, J.G.F.; Tavazzi, L.; Daubert, C.; et al. Surface electrocardiogram to predict outcome in candidates for cardiac resynchronization therapy: A subanalysis of the CARE-HF trial. Eur. J. Heart Fail. 2009, 11, 699-705. [CrossRef] [PubMed]

53. Joshi, N.P.; Stopper, M.M.; Li, J.; Beshai, J.F.; Pavri, B.B. Impact of baseline PR interval on cardiac resynchronization therapy outcomes in patients with narrow QRS complexes: An analysis of the ReThinQ Trial. J. Interv. Card. Electrophysiol. 2015, 43, 145-149. [CrossRef] 
54. Botto, G.L.; Iuliano, A.; Occhetta, E.; Belotti, G.; Russo, G.; Campari, M.; Valsecchi, S.; Stabile, G. A randomized controlled trial of cardiac resynchronization therapy in patients with prolonged atrioventricular interval: The REAL-CRT pilot study. Europace 2020, 22, 299-305. [CrossRef]

55. Zanon, F.; Ellenbogen, K.A.; Dandamudi, G.; Sharma, P.S.; Huang, W.; Lustgarten, D.L.; Tung, R.; Tada, H.; Koneru, J.N.; Bergemann, T.; et al. Permanent His-bundle pacing: A systematic literature review and meta-analysis. Europace 2018, 20, 1819-1826. [CrossRef] [PubMed]

56. Shimony, A.; Eisenberg, M.J.; Filion, K.B.; Amit, G. Beneficial effects of right ventricular non-apical vs. apical pacing: A systematic review and meta-analysis of randomized-controlled trials. Europace 2012, 14, 81-91. [CrossRef] [PubMed]

57. Leclercq, C.; Sadoul, N.; Mont, L.; Defaye, P.; Osca, J.; Mouton, E.; Isnard, R.; Habib, G.; Zamorano, J.; Derumeaux, G.; et al. Comparison of right ventricular septal pacing and right ventricular apical pacing in patients receiving cardiac resynchronization therapy defibrillators: The SEPTAL CRT Study. Eur. Heart J. 2016, 37, 473-483. [CrossRef] [PubMed]

58. Ploux, S.; Eschalier, R.; Whinnett, Z.I.; Lumens, J.; Derval, N.; Sacher, F.; Hocini, M.; Jaïs, P.; Dubois, R.; Ritter, P.; et al. Electrical dyssynchrony induced by biventricular pacing: Implications for patient selection and therapy improvement. Heart Rhythm 2015, 12, 782-791. [CrossRef] [PubMed]

59. Leclercq, C.; Cazeau, S.; Le Breton, H.; Ritter, P.; Mabo, P.; Gras, D.; Pavin, D.; Lazarus, A.; Daubert, J.C. Acute hemodynamic effects of biventricular DDD pacing in patients with end-stage heart failure. J. Am. Coll. Cardiol. 1998, 32, 1825-1831. [CrossRef]

60. Ruschitzka, F.; Abraham, W.T.; Singh, J.P.; Bax, J.J.; Borer, J.S.; Brugada, J.; Dickstein, K.; Ford, I.; Gorcsan, J.; Gras, D.; et al. Cardiac-Resynchronization Therapy in Heart Failure with a Narrow QRS Complex. New Engl. J. Med. 2013, 369, $1395-1405$. [CrossRef]

61. Dandamudi, G.; Vijayaraman, P. The Complexity of the His Bundle: Understanding Its Anatomy and Physiology through the Lens of the Past and the Present. Pacing Clin. Electrophysiol. 2016, 39, 1294-1297. [CrossRef] [PubMed]

62. Beer, D.; Sharma, P.S.; Subzposh, F.A.; Naperkowski, A.; Pietrasik, G.M.; Durr, B.; Qureshi, M.; Panikkath, R.; Abdelrahman, M.; Williams, B.A.; et al. Clinical Outcomes of Selective Versus Nonselective His Bundle Pacing. JACC Clin. Electrophysiol. 2019, 5, 766-774. [CrossRef]

63. Vijayaraman, P.; Herweg, B.; Dandamudi, G.; Mittal, S.; Bhatt, A.G.; Marcantoni, L.; Naperkowski, A.; Sharma, P.S.; Zanon, F. Outcomes of His-bundle pacing upgrade after long-term right ventricular pacing and/or pacing-induced cardiomyopathy: Insights into disease progression. Heart Rhythm 2019, 16, 1554-1561. [CrossRef]

64. Abdelrahman, M.; Subzposh, F.A.; Beer, D.; Durr, B.; Naperkowski, A.; Sun, H.; Oren, J.W.; Dandamudi, G.; Vijayaraman, P. Clinical Outcomes of His Bundle Pacing Compared to Right Ventricular Pacing. J. Am. Coll. Cardiol. 2018, 71, 2319-2330. [CrossRef]

65. Lustgarten, D.L.; Calame, S.; Crespo, E.M.; Calame, J.; Lobel, R.; Spector, P.S. Electrical resynchronization induced by direct His-bundle pacing. Heart Rhythm 2010, 7, 15-21. [CrossRef]

66. Teng, A.E.; Lustgarten, D.L.; Vijayaraman, P.; Tung, R.; Shivkumar, K.; Wagner, G.S.; Ajijola, O.A. Usefulness of His Bundle Pacing to Achieve Electrical Resynchronization in Patients wWith Complete Left Bundle Branch Block and the Relation Between Native QRS Axis, Duration, and Normalization. Am. J. Cardiol. 2016, 118, 527-534. [CrossRef] [PubMed]

67. Ajijola, O.A.; Upadhyay, G.A.; Macias, C.; Shivkumar, K.; Tung, R. Permanent His-bundle pacing for cardiac resynchronization therapy: Initial feasibility study in lieu of left ventricular lead. Heart Rhythm 2017, 14, 1353-1361. [CrossRef] [PubMed]

68. Barba-Pichardo, R.; Sánchez, A.M.; Fernández-Gómez, J.M.; Moriña-Vázquez, P.; Venegas-Gamero, J.; Herrera-Carranza, M. Ventricular resynchronization therapy by direct His-bundle pacing using an internal cardioverter defibrillator. Europace 2013, 15, 83-88. [CrossRef] [PubMed]

69. Sharma, P.S.; Dandamudi, G.; Herweg, B.; Wilson, D.; Singh, R.; Naperkowski, A.; Koneru, J.N.; Ellenbogen, K.A.; Vijayaraman, P. Permanent His-bundle pacing as an alternative to biventricular pacing for cardiac resynchronization therapy: A multicenter experience. Heart Rhythm 2018, 15, 413-420. [CrossRef] [PubMed]

70. Lustgarten, D.L.; Crespo, E.M.; Arkhipova-Jenkins, I.; Lobel, R.; Winget, J.; Koehler, J.; Liberman, E.; Sheldon, T. His-bundle pacing versus biventricular pacing in cardiac resynchronization therapy patients: A crossover design comparison. Heart Rhythm 2015, 12, 1548-1557. [CrossRef]

71. Moss, A.J.; Hall, W.J.; Cannom, D.S.; Klein, H.; Brown, M.W.; Daubert, J.P.; Estes, N.A.M.; Foster, E.; Greenberg, H.; Higgins, S.L.; et al. Cardiac-Resynchronization Therapy for the Prevention of Heart-Failure Events. N. Engl. J. Med. 2009, 361, $1329-1338$. [CrossRef] [PubMed]

72. Sharma, P.S.; Naperkowski, A.; Bauch, T.D.; Chan, J.Y.S.; Arnold, A.D.; Whinnett, Z.I.; Ellenbogen, K.A.; Vijayaraman, P. Permanent His Bundle Pacing for Cardiac Resynchronization Therapy in Patients with Heart Failure and Right Bundle Branch Block. Circ. Arrhythmia Electrophysiol. 2018, 11, e006613. [CrossRef] [PubMed]

73. Arnold, A.D.; Shun-Shin, M.J.; Keene, D.; Howard, J.P.; Sohaib, S.M.A.; Wright, I.J.; Cole, G.D.; Qureshi, N.A.; Lefroy, D.C.; Koa-Wing, M.; et al. His Resynchronization Versus Biventricular Pacing in Patients with Heart Failure and Left Bundle Branch Block. J. Am. Coll. Cardiol. 2018, 72, 3112-3122. [CrossRef] [PubMed]

74. Burri, H.; Jastrzebski, M.; Vijayaraman, P. Electrocardiographic Analysis for His Bundle Pacing at Implantation and Follow-Up. JACC Clin. Electrophysiol. 2020, 6, 883-900. [CrossRef] 
75. Upadhyay, G.A.; Vijayaraman, P.; Nayak, H.M.; Verma, N.; Dandamudi, G.; Sharma, P.S.; Saleem, M.; Mandrola, J.; Genovese, D.; Tung, R. His Corrective Pacing or Biventricular Pacing for Cardiac Resynchronization in Heart Failure. J. Am. Coll. Cardiol. 2019, 74, 157-159. [CrossRef]

76. Huang, W.; Su, L.; Wu, S.; Xu, L.; Xiao, F.; Zhou, X.; Ellenbogen, K.A. A Novel Pacing Strategy with Low and Stable Output: Pacing the Left Bundle Branch Immediately Beyond the Conduction Block. Can. J. Cardiol. 2017, 33, 1736.e1-1736.e3. [CrossRef]

77. Vijayaraman, P.; Subzposh, F.A.; Naperkowski, A.; Panikkath, R.; John, K.; Mascarenhas, V.; Bauch, T.D.; Huang, W. Prospective evaluation of feasibility and electrophysiologic and echocardiographic characteristics of left bundle branch area pacing. Heart Rhythm 2019, 16, 1774-1782. [CrossRef]

78. Huang, W.; Wu, S.; Vijayaraman, P.; Su, L.; Chen, X.; Cai, B.; Zou, J.; Lan, R.; Fu, G.; Mao, G.; et al. Cardiac Resynchronization Therapy in Patients with Nonischemic Cardiomyopathy Using Left Bundle Branch Pacing. JACC Clin. Electrophysiol. 2020, 6, 849-858. [CrossRef]

79. Vijayaraman, P.; Chung, M.K.; Dandamudi, G.; Upadhyay, G.A.; Krishnan, K.; Crossley, G.; Campbell, K.B.; Lee, B.K.; Refaat, M.M.; Saksena, S.; et al. His Bundle Pacing. J. Am. Coll. Cardiol. 2018, 72, 927-947. [CrossRef]

80. Udo, E.O.; Zuithoff, N.P.A.; Van Hemel, N.M.; De Cock, C.C.; Hendriks, T.; Doevendans, P.A.; Moons, K.G.M. Incidence and predictors of short- and long-term complications in pacemaker therapy: The FOLLOWPACE study. Heart Rhythm 2012, 9, 728-735. [CrossRef]

81. Kirkfeldt, R.E.; Johansen, J.B.; Nohr, E.A.; Jørgensen, O.D.; Nielsen, J.C. Complications after cardiac implantable electronic device implantations: An analysis of a complete, nationwide cohort in Denmark. Eur. Heart J. 2014, 35, 1186-1194. [CrossRef] [PubMed]

82. Brunner, M.P.; Cronin, E.M.; Wazni, O.; Baranowski, B.; Saliba, W.I.; Sabik, J.F.; Lindsay, B.D.; Wilkoff, B.L.; Tarakji, K.G. Outcomes of patients requiring emergent surgical or endovascular intervention for catastrophic complications during transvenous lead extraction. Heart Rhythm 2014, 11, 419-425. [CrossRef] [PubMed]

83. Tarakji, K.G.; Wazni, O.M.; Harb, S.; Hsu, A.; Saliba, W.; Wilkoff, B.L. Risk factors for 1-year mortality among patients with cardiac implantable electronic device infection undergoing transvenous lead extraction: The impact of the infection type and the presence of vegetation on survival. Europace 2014, 16, 1490-1495. [CrossRef] [PubMed]

84. Reddy, V.Y.; Knops, R.E.; Sperzel, J.; Miller, M.A.; Petru, J.; Simon, J.; Sediva, L.; De Groot, J.R.; Tjong, F.V.Y.; Jacobson, P.; et al. Permanent leadless cardiac pacing: Results of the LEADLESS trial. Circulation 2014, 129, 1466-1471. [CrossRef] [PubMed]

85. Reddy, V.Y.; Exner, D.V.; Cantillon, D.J.; Doshi, R.; Bunch, T.J.; Tomassoni, G.F.; Friedman, P.A.; Estes, N.A.M.; Ip, J.; Niazi, I.; et al. Percutaneous Implantation of an Entirely Intracardiac Leadless Pacemaker. N. Engl. J. Med. 2015, 373, 1125-1135. [CrossRef]

86. Lakkireddy, D.; Knops, R.; Atwater, B.; Neužil, P.; Ip, J.; Gonzalez, E.; Friedman, P.; Defaye, P.; Exner, D.; Aonuma, K.; et al. A worldwide experience of the management of battery failures and chronic device retrieval of the Nanostim leadless pacemaker. Heart Rhythm 2017, 14, 1756-1763. [CrossRef]

87. Richter, S.; Döring, M.; Ebert, M.; Bode, K.; Müssigbrodt, A.; Sommer, P.; Husser, D.; Hindricks, G. Battery Malfunction of a Leadless Cardiac Pacemaker: Worrisome Single-Center Experience. Circulation 2018, 137, 2408-2410. [CrossRef]

88. Jung, W.; Sadeghzadeh, G.; Jäckle, S.; Roggenbuck-Schwilk, B.; Zvereva, V.; Kohler, J. Successful implant of a leadless pacemaker with tine-based fixation next to an abandoned battery-depleted screw-in helix fixation leadless device. EP Eur. 2018, 20, 500. [CrossRef]

89. Reynolds, D.; Duray, G.Z.; Omar, R.; Soejima, K.; Neuzil, P.; Zhang, S.; Narasimhan, C.; Steinwender, C.; Brugada, J.; Lloyd, M.; et al. A Leadless Intracardiac Transcatheter Pacing System. N. Engl. J. Med. 2016, 374, 533-541. [CrossRef]

90. Roberts, P.R.; Clementy, N.; Al Samadi, F.; Garweg, C.; Martinez-Sande, J.L.; Iacopino, S.; Johansen, J.B.; Prat, X.V.; Kowal, R.C.; Klug, D.; et al. A leadless pacemaker in the real-world setting: The Micra Transcatheter Pacing System Post-Approval Registry. Heart Rhythm 2017, 14, 1375-1379. [CrossRef]

91. Vaidya, V.R.; Dai, M.; Asirvatham, S.J.; Rea, R.F.; Thome, T.M.; Srivathsan, K.; Mulpuru, S.K.; Kusumoto, F.; Venkatachalam, K.L.; Ryan, J.D.; et al. Real-world experience with leadless cardiac pacing. Pacing Clin. Electrophysiol. 2019, 42, 366-373. [CrossRef] [PubMed]

92. Biffi, M.; Melissano, D.; Rossi, P.; Kaliska, G.; Havlíĉek, A.; Pelargonio, G.; Romero, R.; Guastaferro, C.; Menichelli, M.; Vireca, E.; et al. The OPTI-MIND study: A prospective, observational study of pacemaker patients according to pacing modality and primary indications. Europace 2014, 16, 689-697. [CrossRef] [PubMed]

93. Biffi, M.; Bertini, M.; Saporito, D.; Belotti, G.; Quartieri, F.; Piancastelli, M.; Pucci, A.; Boggian, G.; Mazzocca, G.F.; Giorgi, D.; et al. Automatic management of atrial and ventricular stimulation in a contemporary unselected population of pacemaker recipients: The ESSENTIAL Registry. Europace 2016, 18, 1551-1560. [CrossRef] [PubMed]

94. Boveda, S.; Lenarczyk, R.; Haugaa, K.H.; Iliodromitis, K.; Finlay, M.; Lane, D.; Prinzen, F.W.; Dagres, N. Use of leadless pacemakers in Europe: Results of the European Heart Rhythm Association survey. Europace 2018, 20, 555-559. [CrossRef] [PubMed]

95. Miller, M.A.; Neuzil, P.; Dukkipati, S.R.; Reddy, V.Y. Leadless Cardiac Pacemakers Back to the Future. J. Am. Coll. Cardiol. 2015, 66, 1179-1189. [CrossRef]

96. Chinitz, L.; Ritter, P.; Khelae, S.K.; Iacopino, S.; Garweg, C.; Grazia-Bongiorni, M.; Neuzil, P.; Johansen, J.B.; Mont, L.; Gonzalez, E.; et al. Accelerometer-based atrioventricular synchronous pacing with a ventricular leadless pacemaker: Results from the Micra atrioventricular feasibility studies. Heart Rhythm 2018, 15, 1363-1371. [CrossRef] 
97. Steinwender, C.; Khelae, S.K.; Garweg, C.; Chan, J.Y.S.; Ritter, P.; Johansen, J.B.; Sagi, V.; Epstein, L.M.; Piccini, J.P.; Pascual, M.; et al. Atrioventricular Synchronous Pacing Using a Leadless Ventricular Pacemaker: Results from the MARVEL 2 Study. JACC Clin. Electrophysiol. 2020, 6, 94-106. [CrossRef]

98. Zhao, X.; Sun, C.; Cao, M.; Li, H. Atrioventricular block can be used as a risk predictor of clinical atrial fibrillation. Clin. Cardiol. 2019, 42, 452-458. [CrossRef]

99. Lamas, G.A.; Ellenbogen, K.A.; Hennekens, C.H.; Montanez, A. Evidence Base for Peacemaker Mode Selection from Physiology to Randomized Trials. Circulation 2004, 109, 443-451. [CrossRef] 